\title{
MANAGING AND REDUCING TOTAL CYCLE TIME: MODELS AND ANALYSIS
}

\author{
by \\ John Miltenburg \\ David Sparling \\ School of Business \\ McMaster University \\ Innovation Research Working Group \\ WORKING PAPER NO.27
}

August, 1993

\begin{abstract}
The Working Paper series is intended as a means whereby a researcher may communicate his or her thoughts and findings to interested readers for their comments. The paper should be considered preliminary in nature and may require substantial revision. Accordingly, this Working Paper should not be quoted nor the data referred to without the written consent of the author. Your comments and suggestions are welcome and should be directed to the author.
\end{abstract}

$\ln \operatorname{lis}$

HiD

45

.6657

no. 27 
Working Paper

\title{
Managing and Reducing Total Cycle Time: \\ Models And Analysis
}

\author{
August 1993 \\ John Miltenburg \\ David Sparling
Michael DeGroote School of Business
McMaster University
1280 Main Street West
Hamilton, Ontario L8S 4M4
Canada

Telephone: (416) 525-9140 extension 3943

FAX: (416) 527-0100

\begin{abstract}
Acknowledgement
This research was supported by the Natural Sciences and Engineering Research Council of Canada under Grant No. A5474.
\end{abstract}




\title{
Managing and Reducing Total Cycle Time:
}

\section{Models And Analysis}

\begin{abstract}
Cycle time management and reduction, CTM, is the manufacturing philosophy that follows TQM and JIT. CTM seeks to reduce the total time required to perform all the activities that occur during order processing, design, supply management, production and distribution of a product or service.

Three models are developed for supporting CTM -- a simple stochastic model, a Markov chain model and a queueing model. The models must be fitted to the manufacturing environment in which they will be used. Three manufacturing environments -- make to order, assemble to order and make to stock -- are described. When a CTM model is applied to a manufacturing environment it identifies the activities that represent the largest components of cycle time. Those activities are then targeted for cycle time reduction.
\end{abstract}

Keywords: Cycle Time Management; Cycle Time reduction; Improving Manufacturing 


\section{Introduction}

From the middle of the 1960's through the 70's and early 80's, productivity in the manufacturing sectors of the North American and European economies lagged dramtically behind productivity in Japan. Consequently Japan was able to offer products at lower prices, and its share of world exports rose (Figure 1). Much of this success in raising productivity in the manufacturing sector was attributed to a new manufacturing philosophy called the Toyota Production System. The system was developed by Toyota in the 1950's and 60's as a means for reducing production costs (Monden [1983], Ohno [1988]). During this time it slowly spread to Toyota's suppliers and to a few other Japanese manufacturers.

Then in the early 1970's (after an oil embargo in 1973) oil prices rose sharply. This precipitated sharp increases in production costs for Japanese companies. In response, many of these companies quickly moved to implement elements of the Toyota Production System into their operations. The implementation was difficult, but the crisis caused by rising oil prices and Japan's desperate lack of space and other natural resources ensured that everyone worked together to make it successful. After all the alternative was bankruptcy. Before long significant improvements in cost and quality were being noticed.

Ten years later in the early 1980's, North American manufacturers in industries such as steel, automotive, machine tools, and electronics were facing the same problem -- namely, rising production costs (with no end in sight). One of the many causes was a poor level of quality. The results were products that could not compete and organizations that either had to change or go out of business.

Like the Japanese manufacturers in the early 1970's, the economic emergency forced 


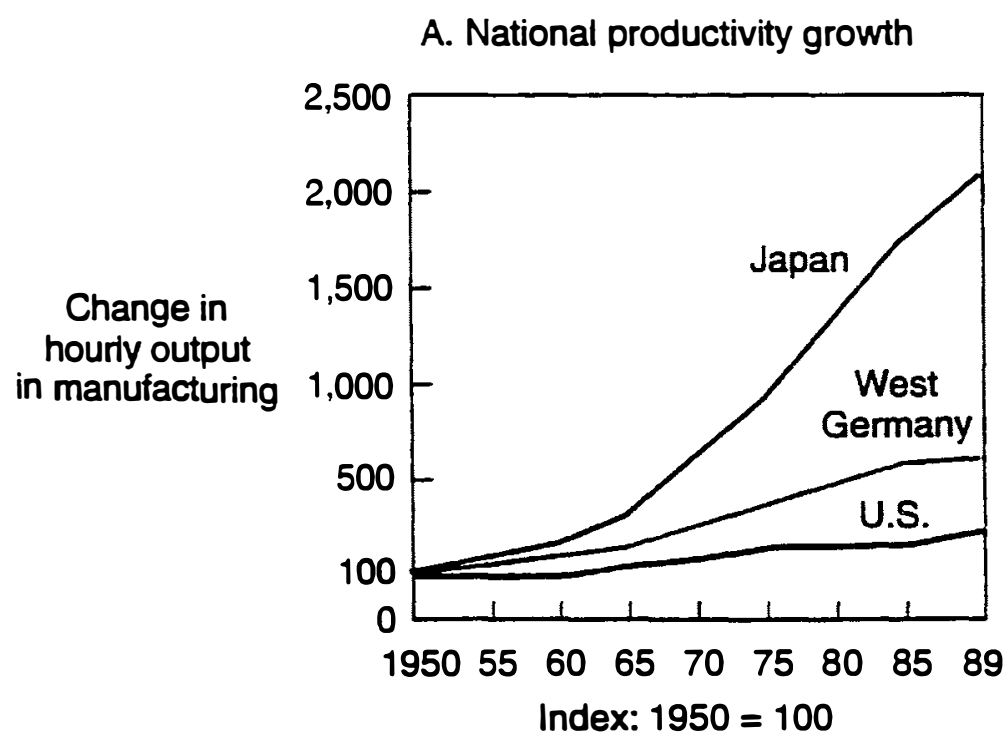

B. World exports

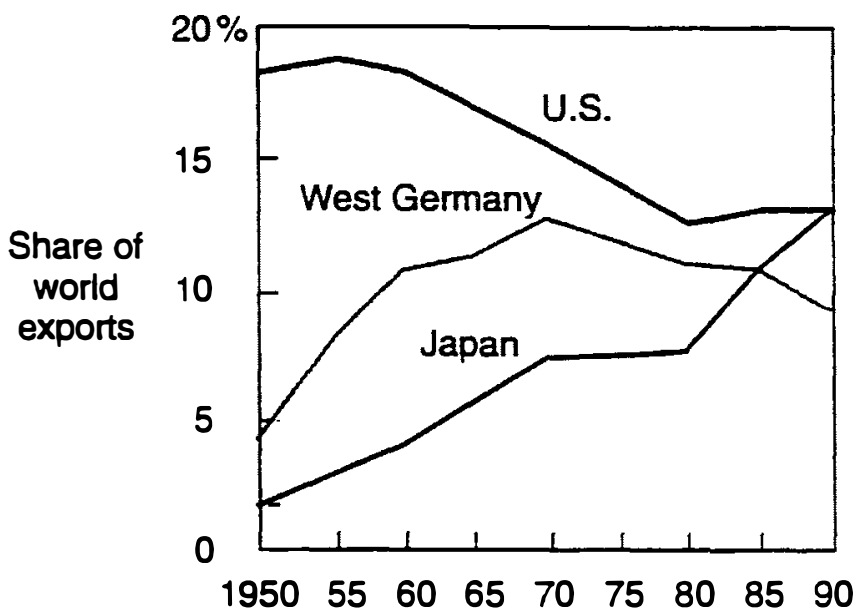

Source: Chase and Aquilano [p. 30, 1992] and Fortune, Special Issue, Spring/Summer 1991.

Fiqure 1 -- A Comparison of Productivity Growth and Export Growth 
some of these North American manufacturers to consider new ways of doing business. Many decided to implement the new production system developed by Toyota. By now the new system was called Just-In-Time (Schonberger [1982], Hall [1983]). The new system was difficult to implement, but by 1987 those who were successful were reporting productivity and quality levels comparable to the Japanese (Figures 2 and 3).

\section{What Comes After Just-In-Time}

Many manufacturers have taken total quality management, TQM, and just-in-time, JTT, to the furthest extent possible and find that they need more improvements in cost, quality, delivery and flexibility. The philosophy that follows TQM and JIT in making this possible is cycle time management/reduction. Since the mid-1980's the Japanese have led the way (and were followed by some North American manufacturers) in using this philosophy to provide more flexibility and shorter delivery times. One area when dramatic improvements have been made is the time required to develop new products. Moody [p. 198, 1990] reports that:

- Japanese manufacturers of projection televisions can develop systems in one-third of the time required by U.S. companies,

- Japanese manufacturers of molds for injection molding machines can develop molds in one-third the time required by U.S. companies and at a cost that is 30 percent lower, and

- Japanese automobile manufacturers are developing new cars in half the time and with half as many people as are required by U.S. companies.

Other examples are listed in Figure 4.

Cycle time management looks at all the activities that occur during the manufacturing cycle. This includes the white collar activities that occur when a customer order is taken, 


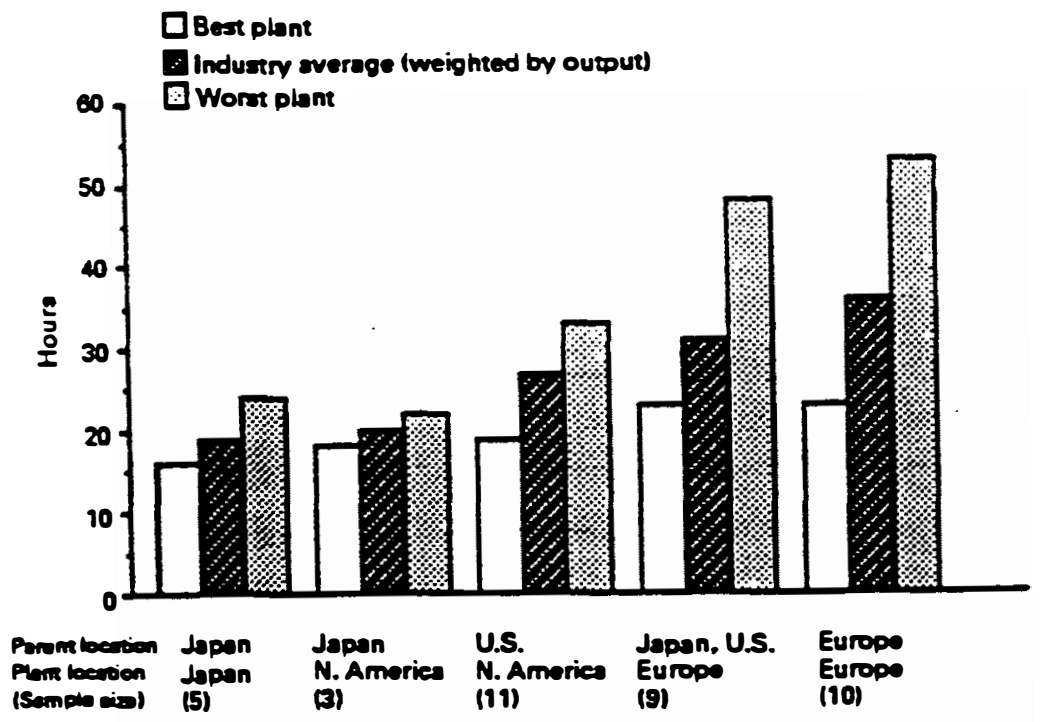

"Hours" is a measure of the total number of hours required to complete a set of standard manufacturing activities on a standard vehicle in assembly plants ruming at full output.

Notice that by 1986/1987 the hours required by all Japanese plants located in North America and the best U.S. plant located in North America was comparable to average Japanese plants located in Japan. Other North American plants and plants in Europe still have a long way to go.

The data were obtained from a 1986/1987 survey conducted by the MIT International Motor Vehicle Program.

Source: Dertouzos, Lester and Sol ow [p. 185, 1990] 


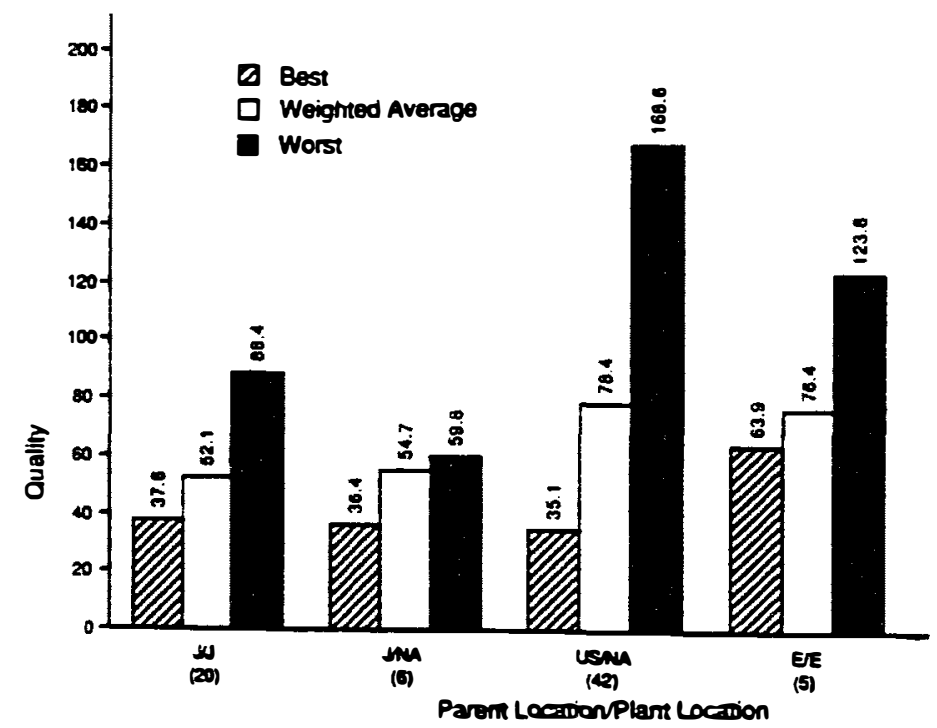

"Defects" is a measure of quality. It is the number of owner-reported defects per vehicle in the first three months of use, per 100 vehicles.

Notice that by 1989 the quality at all Japanese plants located in North America and the best U.S. plant located in North America was comparable to quality at Japanese plants located in Japan. The quality level at U.S. plants located in North America and plants located in Europe still lagged behind the Japanese. U.S. plants were having more difficulty matching Japanese levels of quality than matching productivity (Figure 2).

The data were obtained by J.D. Power and Associates and the MIT International Motor Vehicle Program.

Source: Womack, Jones and Roos [p. 86, 1990] 


\begin{tabular}{llll} 
& & \multicolumn{2}{c}{ Development Time } \\
\cline { 4 - 4 } Company & New Product & Before & Now \\
\hline Honda & Automobiles & 5 years & 3 years \\
AT\&T & Telephones & 2 years & 1 year \\
Navistar & Trucks & 5 years & 2.5 years \\
Hewiett-Packard & Printers & 4.5 years & 22 months
\end{tabular}

Source: Moody [p. 199, 1990] and Fortune, February 13, 1989

Figure 4 -- Improvements in Product Development Time 
product design activities, activities at suppliers of raw materials and component suppliers, manufacturing activities, and activities associated with shipping products to customers. The many activities that constitute the manufacturing cycle can be organized into the five sub-cycles shown in Figure 5. Clearly the interactions between the activities and sub-cycles that comprise the manufacturing cycle are complex.

For many manufacturers, the objective is to reduce the overall manufacturing cycle time. This usually requires that the cycle times of each of the sub-cycles within the manufacturing cycle be reduced. It is believed that reducing the overall cycle time will accomplish two purposes.

1. Costs and delivery time will be reduced and quality will be improved.

Reducing overall manufacturing cycle time results in less time being available for all the activities that are currently done. This will force the unnecessary activities to be eliminated, and the necessary ones to be improved (so that they can be done faster). Lower costs will result. Quality will improve because the activities associated with poor quality will be eliminated or improved.

2. The time and cost required to develop new products will be reduced.

This paper is organized as follows. Three manufacturing environments - make to order, assemble to order, and make to stock -- are defined in section 2. A simple stochastic model of cycle time management/reduction is developed in section 3. A Markov chain model is discussed in section 4. A queueing model is presented in section 5. These models provide useful tools to managers charged with managing and reducing cycle time. Conclusions and areas for future research are discussed in section 6 . 


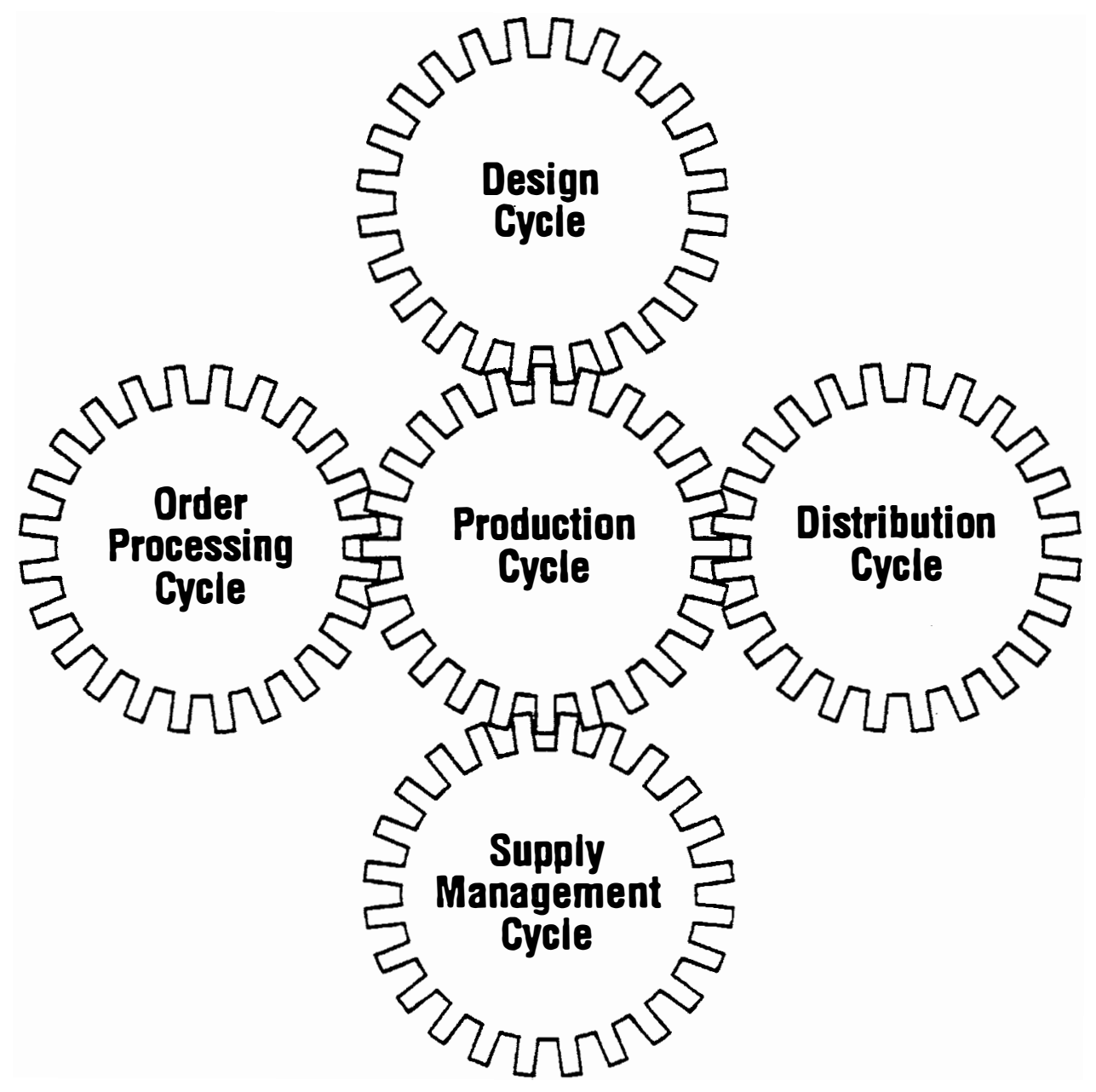

Ficure 5 -- The Five sub-cycles Within Total Crale Time 


\section{Manufacturing Cvcle Time In Different Manufacturing Environments}

Five sub-cycles form the manufacturing cycle. The activities that comprise each subcycle are listed in Figure 6. Three different manufacturing environments can be identified, MTO, ATO and MTS -- make to order, assemble to order, and make to stock. From the perspective of cycle time, the differences between these environments lie in specific activities and the times at which these activities are undertaken.

\section{Make To Order, MTO}

In MTO, the sub-cycles are undertaken sequentially as depicted in Figure 7.

Sales and technical personnel work with a customer to develop the specifications, delivery and price that constitute an order.

The order is sent to the design department for detailed product and component design work. After the customer approves the final design, bills of material and process plans are developed.

The supply management sub-cycle follows. Decisions are made to outsource components. Suppliers are selected, terms are arranged and orders are released. Orders for tooling are also released. Suppliers are monitored to ensure that good quality materials arrive on time.

Following receipt of purchased materials and tooling, activities in the production subcycle begin. Schedules are developed, materials are moved, parts are fabricated, and products are assembled. After testing, products are reworked if necessary.

The finished products are then collected to complete the customer order. The order is shipped to the customer and, at the same time, an invoice is sent to the customer.

The cycle time that the customer sees in the MTO environment is long. It begins with 


\section{Order Processing Sub-Cycle}

1. Respond to customer inquiry

2. Create sales order

- Develop specifications

- Determine delivery

- Determine price

- Check customer credit

3. Receive customer approval

\section{Design Sub-Cycle}

1. Design new products

- Conduct market research

- Analyze product technology

- Develop prototype

2. Design new components

3. Modify standard design to meet customer requirements

4. Obtain customer approval for new design

5. Develop bills of material and process plans

\section{Supply Management Sub-Cycle}

1. Make versus buy decisions

2. Identify, evaluate and develop suppliers

3. Negotiate terms

- Determine quantity, quality, delivery and price

4. Release orders for materials and components (actual, forecast)

5. Release orders for tooling

6. Monitor suppliers to ensure quantity quality, delivery and price

7. Inventory purchased material and parts

\section{Production Sub-Cycle}

1. Production planning and control

2. Materials management

3. Fabricate parts

4. Assemble products

5. Inspection, testing and rework

6. Inventory of finished products

7. Maintenance

\section{Distribution}

1. Ship products to distribution centers

2. Pick products for customer orders

3. Ship products to customer; invoice customer

Figure 6 - Activities in the Sub-Cycles of Manufacturing Cvcle Time 


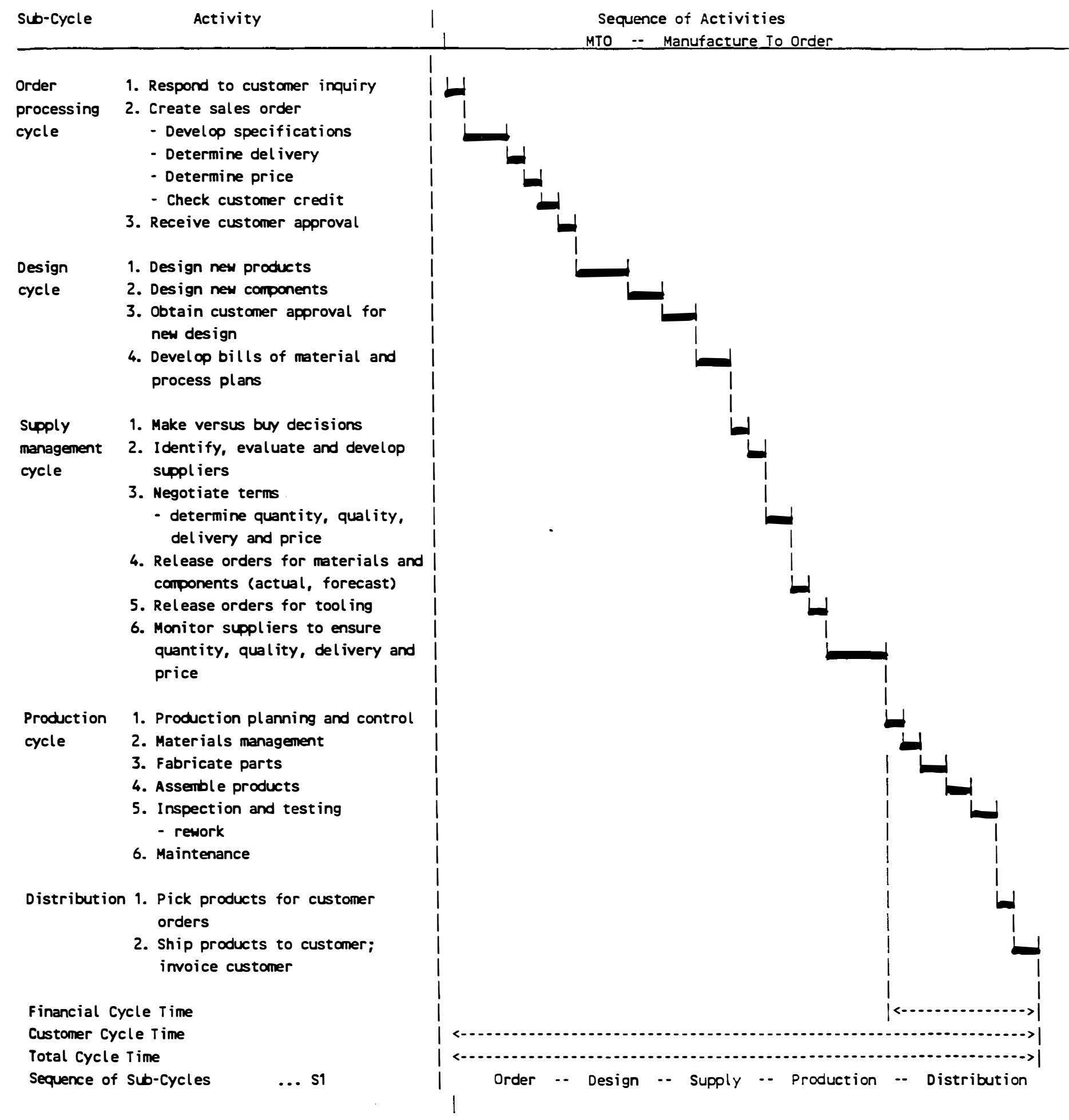

Figure 7 .. Sequence of Activities in an MTO Envirorment 
the initial inquiry and ends when the customer receives the product (and invoice). The financial cycle for the company is relatively short (compared to other production environments). It begins when the company receives the purchased materials and components and ends when the customer pays the invoice.

Assemble To Order, ATO

In an ATO environment unique products are assembled from standard components. The standard components are produced for inventory so that they will be available when a customer order is obtained. The activities in the sub-cycles form two sequences as depicted in Figure 8.

Sequence S1 consists of activities that relate to the specific customer orders. Sequence S2 consists of the activities undertaken to design, supply and produce the standard components.

In this environment the order processing sub-cycle is the same as it was in the MTO environment. The activities in the supply management sub-cycle relate to the purchase of material for the standard components and the management of inventories.

Some activities in the production sub-cycle relate to the production or fabrication of the standard components (sequence S2). The other activities relate to the production or assembly of the unique products (sequence $\mathrm{S} 1$ ) from the standard components.

The activities in the distribution sub-cycle are the same as those in the MTO environment.

The advantage of the ATO environment is its short Customer Cycle Time compared to the MTO environment. However the cost of achieving this is a longer Financial Cycle Time, and likely a longer Total Cycle Time. 


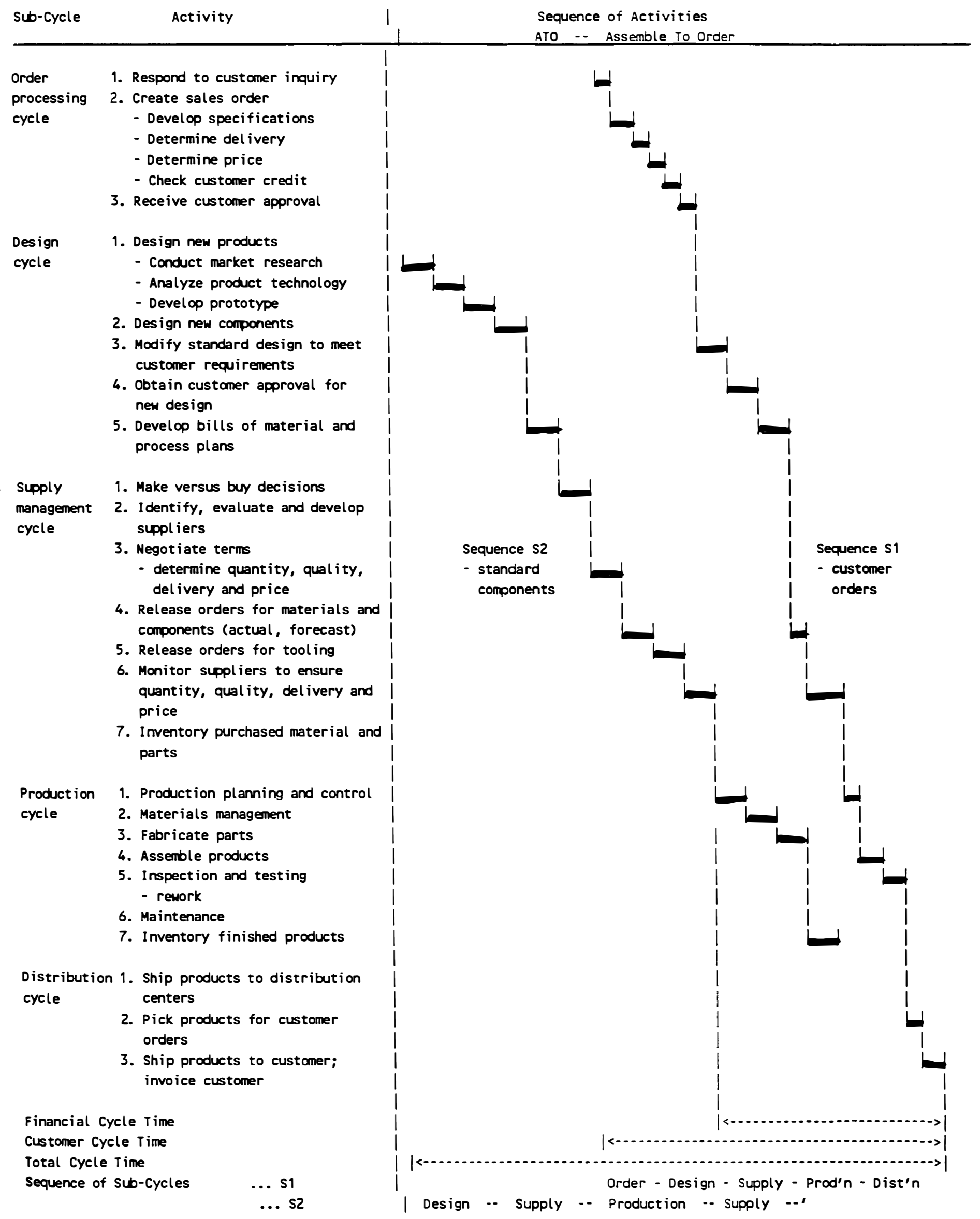


Make To Stock, MTS

The MTS environment tries to reduce further the Customer Cycle Time by producing standard products for inventory (compared to producing only standard components for inventory in the ATO environment). The activities in the sub-cycles are arranged into two sequences as depicted in Figure 9. Those activities associated with processing customer orders form sequence S1, while those activities undertaken to design, supply and produce the standard components form sequence $S 2$.

The activities in the order sub-cycle are simpler than those in the ATO environment because no product specifications need to be developed.

All design, supply and production sub-cycle activities are related to the standard components and products (sequence S2), which are produced according to forecasts of customer requirements. The finished products are stored in inventory at distribution centers to meet future customer orders. 
Order processing cycle

1. Respond to customer inquiry

2. Create sales order

- Determine delivery

- Check customer credit

Design

cyele

1. Design new products

- Conduct market research

- Analyze product technology

- Develop prototype

2. Design new components

3. Develop bills of material and process plans

Supply 1. Make versus buy decisions

eanagement 2. Identify, evaluate and develop cycle suppliers

3. Negotiate terms

- determine quantity, quality, delivery and price

4. Release orders for materials and components (actual, forecast)

5. Release orders for tool ing

6. Monitor suppliers to ensure quantity, quality, delivery and price

Production

1. Production planning and control cycle

2. Materials management

3. Fabricate parts

4. Assemble products

5. Inspection and testing - rework

6. Maintenance

7. Inventory finished products

Distribution 1. Ship products to distribution cycle centers

2. Pick products for customer orders

3. Ship products to customer; invoice customer

Financial Cycle Time Customer Cycle Time Total Cycle Time Sequence of Sub-Cycles

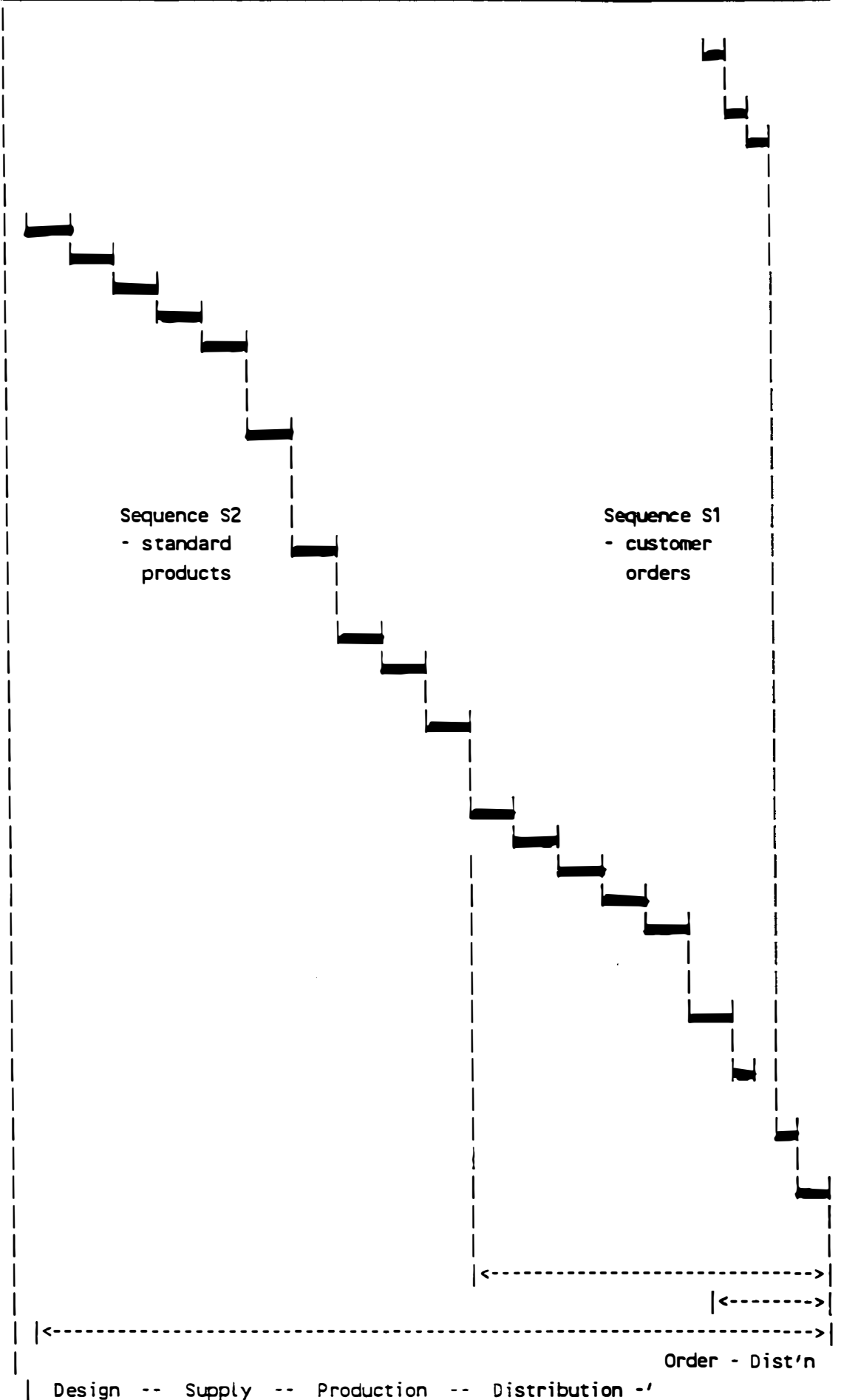




\section{A Simple Stochastic Model}

Define the following notation.

$\mathrm{U} \quad$ - manufacturing environment, $\mathrm{U}=\{\mathrm{MTO}, \mathrm{ATO}, \mathrm{MTS}\}$.

V - sub-cycle, $\mathrm{V}=\{$ Order Processing, Design, Supply Management, Production, Distribution\}.

$S_{j} \quad-\quad$ sequence of sub-cycles, $j=1,2$.

$\mathrm{p} \quad-$ an order or product, $\mathrm{p}=1,2,3, \ldots$

$\tilde{\mathfrak{t}}_{\mathrm{v}, \mathrm{p}}^{\mathrm{U}, \mathrm{S}_{j}}$ - a random variable denoting the time required to complete all the activities in subcycle $\mathrm{V}$ for order or product $\mathrm{p}$, under sequence $S_{\mathrm{j}}$ in environment $\mathrm{U}$.

$\tilde{\mathrm{T}}_{\mathrm{P}}^{\mathrm{U}, \mathrm{S}_{\mathrm{j}}}=\sum_{\mathrm{V}} \tilde{\mathrm{t}}_{\mathrm{V}_{\mathrm{p}} \mathrm{U}}^{\mathrm{U}, \mathrm{S}_{\mathrm{P}}}$ - a random variable denoting the total time required to complete all the subcycles for order or product $p$, under sequence $S_{j}$ in environment $U$.

The performance measures are:

FCT - the financial cycle time,

CCT - the customer cycle time,

TCT - the total cycle time, and

TT - the total time, TT.

The computation of these measures varies depending upon the particular manufacturing environment (Figures 7, 8 and 9).

Financial Cycle Time, FCT

Let $V_{F}$ denote the financial cycle. Then $V_{F}=$ Production Cycle $\cup$ Distribution Cycle, and 
$\mathrm{FCT} \tilde{\mathrm{T}}_{\mathrm{P}}^{\mathrm{U}}=\sum_{\mathrm{S}_{\mathrm{j}}} \sum_{\mathrm{V}_{\mathrm{F}}} \tilde{\mathrm{t}}_{\mathrm{V}_{\mathrm{F}, \mathrm{P}}}^{\mathrm{U}, \mathrm{s}_{\mathrm{P}}}-$ a random variable denoting the total financial cycle time for order or product $\mathrm{p}$ in manufacturing environment $\mathrm{U}$.

\section{Customer Cycle Time, CCT}

Let $\mathrm{V}_{\mathrm{C}}$ denote the customer cycle. $\mathrm{V}_{\mathrm{C}}=\left\{\mathrm{V} \in \mathrm{S}_{1}\right\}$. Then

$$
\begin{aligned}
& C C \tilde{T}_{\mathrm{p}}^{U}=\sum_{\mathrm{v}_{\mathrm{C}}} \tilde{\mathrm{t}}_{\mathrm{v}_{\mathrm{C}}, \mathrm{P}}^{\mathrm{U}, \mathrm{s}_{1}}-\quad \text { a random variable denoting the customer cycle time for order or } \\
& \text { product } \mathrm{p} \text { in manufacturing environment } \mathrm{U} \text {. }
\end{aligned}
$$

\section{Total Cycle Time, TCT}

The computation of total cycle time depends on the manufacturing environment. In the MTO environment,

$$
\operatorname{TCT}_{\mathrm{p}}^{\mathrm{MTO}}=\sum_{\mathrm{V} \in \mathrm{S}_{1}} \tilde{\mathrm{t}}_{\mathrm{V}, \mathrm{p}}^{\mathrm{MTO}, \mathrm{s}_{1}}
$$

In the ATO environment (Figure 8), define

$$
\mathrm{V}_{\mathrm{T}}^{\text {ATO }}=\left\{\mathrm{V} \in \mathrm{S}_{2} \text {, Production } \in \mathrm{S}_{1} \text {, Distribution } \in \mathrm{S}_{1}\right\} \text {. Then }
$$

$\operatorname{TCT}_{\mathrm{p}}^{\mathrm{ATO}}=\sum_{s_{\mathrm{j}}} \sum_{\mathrm{V}_{\mathrm{T}}^{\text {ATO }}} \tilde{\mathrm{t}}_{\mathrm{V}_{\mathrm{T}}^{\mathrm{ATO}}, \mathrm{P}}^{\mathrm{ATO}, \mathrm{s}_{\mathrm{j}}}$

In the MTS environment, define $\mathrm{V}_{\mathrm{T}}^{\mathrm{MTS}}=\left\{\mathrm{V} \in \mathrm{S}_{2}\right.$, Distribution $\left.\in \mathrm{S}_{1}\right\}$. Then

$$
\operatorname{TCT}_{\mathrm{p}}^{\mathrm{MTS}}=\sum_{s_{\mathrm{j}}} \sum_{\mathrm{v}_{\mathrm{T}}^{\mathrm{MTS}}} \overline{\mathrm{t}}_{\mathrm{v}_{\mathrm{T}}^{\mathrm{MTS}, \mathrm{p}} \mathrm{MT}}^{\mathrm{MTs}}
$$


Total Time, TT

The total cost of operating the entire system is directly proportional to the time required to complete all the activities in all the sub-cycles in each sequence. That is,

$$
\begin{gathered}
T \tilde{T}_{\mathrm{p}}^{U}=\sum_{\mathbf{S}_{\mathrm{j}}} \sum_{\mathrm{V} \in \mathbf{S}_{\mathrm{j}}} \tilde{\mathbf{t}}_{\mathrm{V}, \mathbf{p}}^{\mathrm{U}, \mathbf{S}_{\mathrm{j}}}-\quad \text { a random variable denoting the total time for order or product } \mathrm{p} \text { in } \\
\text { manufacturing environment } \mathrm{U} .
\end{gathered}
$$

\section{Expectations}

Define the following operators.

E( ) - the expected value for all orders or products.

$\sigma^{2}() \quad$ - the variance over all orders or products.

Then, for example:

$$
E\left(\mathfrak{t}_{\mathrm{V}, \mathrm{p}}^{\mathrm{U}, \mathrm{S}_{j}}\right)=\left[\sum_{\mathrm{p}}^{\mathrm{t}_{\mathrm{V}, \mathrm{p}}^{\mathrm{U}, \mathrm{S}_{\mathrm{j}}}} \operatorname{Pr}(\mathrm{p})\right]
$$

where $\mathbf{t}$ is a realization of $\tilde{\mathrm{t}}$ and $\operatorname{Pr}(\mathrm{p})$ is the fraction of orders or products that are of type $\mathrm{p}$.

\subsection{Analysis of a Simple Stochastic Model}

This simple model assumes that the activity times, $\overline{\mathrm{t}}_{\mathrm{v}, \mathrm{p}}^{\mathrm{U}, \mathrm{S}_{\mathrm{j}}}$, are stationary and independent. In some manufacturing environments the extent of the dependence between some activity times is not negligible. The factors that effect the extent of the dependence are discussed in Appendix 1. While this model ignores dependencies between activity times, the Markov chain model and queueing model that follow in sections 4 and 5 do not. Then 


$$
\begin{aligned}
& \mathrm{E}\left(\mathrm{FC} \tilde{T}_{\mathrm{p}}^{\mathrm{U}}\right)=\sum_{\mathrm{s}_{\mathrm{j}}} \sum_{\mathrm{v}_{\mathrm{p}}} \mathrm{E}\left(\tilde{\mathrm{t}}_{\mathrm{v}_{\mathrm{p}, \mathrm{p}}^{\mathrm{U}}, \mathrm{s}_{\mathrm{j}}}\right) \\
& \sigma^{2}\left(\mathrm{FC} \tilde{T}_{\mathrm{p}}^{\mathrm{U}}\right)=\sum_{\mathrm{s}_{\mathrm{j}}} \sum_{\mathrm{v}_{\mathrm{p}}} \sigma^{2}\left(\tilde{\mathrm{t}}_{\mathrm{v}_{\mathrm{p}}, \mathrm{P}}^{\mathrm{U}, \mathrm{s}_{\mathrm{j}}}\right)
\end{aligned}
$$

$$
\begin{aligned}
& E\left(C C \tilde{T}_{\mathrm{p}}^{\mathrm{U}}\right)=\sum_{\mathrm{v}_{\mathrm{C}}} \mathrm{E}\left(\tilde{\mathrm{t}}_{\mathrm{v}_{\mathrm{C}, \mathrm{p}}^{\mathrm{U}}}^{\mathrm{U} \mathrm{s}_{1}}\right) \\
& \sigma^{2}\left(C C \tilde{T}_{\mathrm{p}}^{\mathrm{U}}\right)=\sum_{\mathrm{v}_{\mathrm{C}}} \sigma^{2}\left(\tilde{\mathrm{t}}_{\mathrm{v}_{\mathrm{C}, \mathrm{p}}}^{\mathrm{U}, \mathrm{S}_{1}}\right)
\end{aligned}
$$

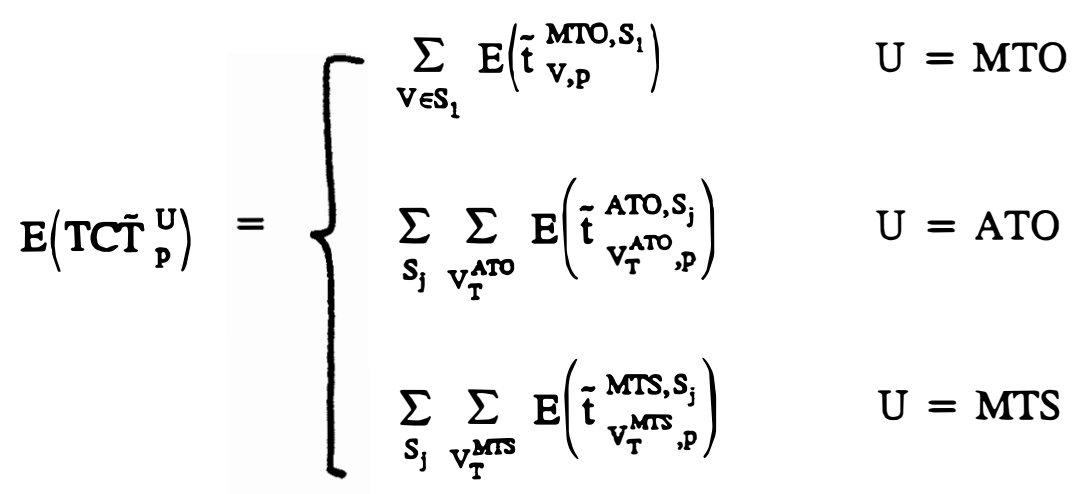

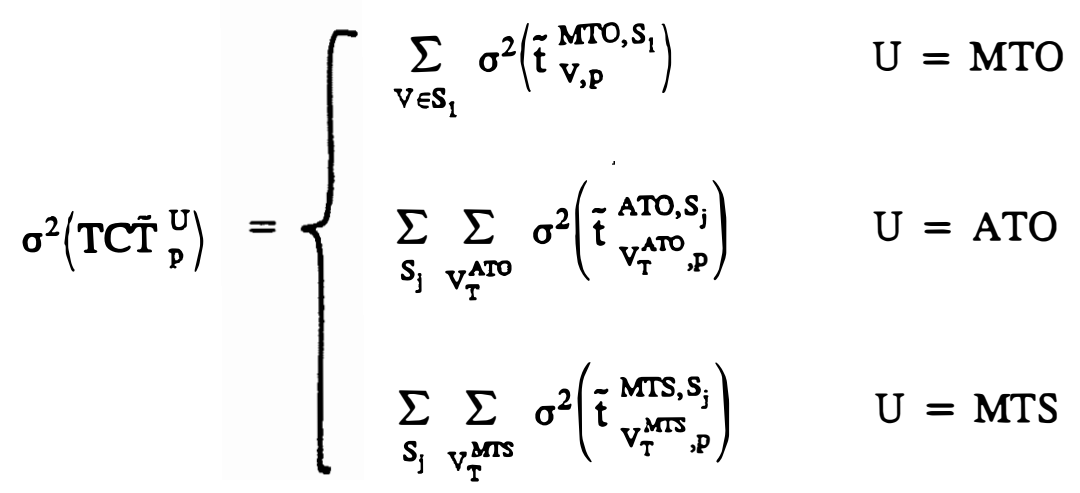

$$
E\left(T \tilde{T}_{p}^{U}\right)=\sum_{S_{j}} \sum_{V \in S_{j}} E\left(\tilde{t}_{v, p}^{U, S_{j}}\right)
$$




$$
\sigma^{2}\left(\tilde{T}_{\mathrm{p}}^{\mathrm{U}}\right)=\sum_{\mathrm{S}_{\mathrm{j}}} \sum_{\mathrm{V} \in \mathrm{S}_{\mathrm{j}}} \sigma^{2}\left(\tilde{\mathrm{t}}_{\mathrm{V}, \mathrm{p}}^{\mathrm{U}, \mathrm{S}_{\mathrm{j}}}\right)
$$

Since a large number of activities are summed to form the financial cycle time, the customer cycle time, the total cycle time, and the total time, the probability density functions of these random variables can be approximated by the normal distribution. (This is a consequence of the central limit theorem.) This makes the calculation of interval estimates very easy.

\section{A Simple Process for Cycle Time Management and Reduction}

All cycle time management/reduction programs seek to:

1. Identify those sub-cycles and the activities within the sub-cycles that represent the largest components of FCT, CCT, TCT and TT, and

2. Reduce the time (expected value and variability) required to do the activities in these sub-cycles.

The following six step process accomplish this.

Step 1. Select a value of $\mathrm{k}$, that reflects the trade-off between the expected value and the standard deviation of the activity times.

Step 2. Select a performance measure PM from $\{F C T, C C T, T C T, T T\}$.

Step 3. Select a sequence $S_{j}$ from $\left\{S_{1}, S_{2}\right\}$.

Step 4. For each activity $i \in S_{j}$ calculate

$$
\begin{aligned}
\delta_{i}^{P M}= & {[E(P M)+k \sigma(P M)]_{\text {with } i} } \\
& -[E(P M)+k \sigma(P M)]_{\text {without } i} .
\end{aligned}
$$

If this is the last sequence go to step 5. Otherwise go to step 3 . 
Step 5. Rank the activities in decreasing order of $\delta_{i}^{\mathrm{PM}}$.

Step 6. Reduce the time required to do the activities ranked highest in step 5.

\section{Example 1a}

Consider a company operating in a MTO environment. The activities that comprise the five sub-cycles of the manufacturing cycle time are listed in Figure 10. The expected value and standard deviation of FCT, CCT, TCT and TT are computed from equations 1 to 6 and shown in Figure 13. Also shown there are some of the results of the six step cycle time management/reduction process. When $\mathrm{k}=2$, activity 3 in the production sub-cycle is the largest component of cycle time, regardless of which performance measure is selected. Consequently it would be targeted for cycle time reduction.

\section{Example 1b}

Figure 11 presents activity times for a company in an ATO environment. Expected values and standard deviations for FCT, CCT, TCT and TT are easily computed (Figure 13). The activities that contribute most to cycle time differ for the various performance measures. If the objective is to reduce total cycle time then activity 1 in the design - standard components sub-cycle, followed by activity 3 in the production - standard components sub-cycle would be targeted for cycle time reduction.

\section{Example 1c}

A company in a Make To Stock environment has the activity times listed in Figure 12. The performance measures are summarized in Figure 13 where the activities contributing most to cycle are also identified. 


\begin{tabular}{|c|c|c|c|c|}
\hline Production & Sub-Cycle & Activity $^{(1)}$ & Act & vity Time ${ }^{(2)}$ \\
\hline Environment & & Number & $\begin{array}{l}\text { Mean } \\
\mathrm{E}()\end{array}$ & $\begin{array}{c}\text { Standard Deviation } \\
\sigma()\end{array}$ \\
\hline MTO & Order & 1 & .5 & .2 \\
\hline & Processing & 2 & 10 & 4 \\
\hline & & 3 & 1 & .5 \\
\hline & Design & 1 & 20 & 5 \\
\hline & & 2 & 10 & 5 \\
\hline & & 3 & 10 & 3 \\
\hline & & 4 & 10 & 3 \\
\hline & Supply & 1 & 3 & .5 \\
\hline & Management & 2 & 2 & .5 \\
\hline & & 3 & 5 & 1 \\
\hline & & 4 & 1 & .2 \\
\hline & & 5 & 2 & .5 \\
\hline & & 6 & 15 & 8 \\
\hline & Production & 1 & 3 & 1 \\
\hline & & 2 & 2 & 1 \\
\hline & & 3 & 15 & 8 \\
\hline & & 4 & 5 & 2 \\
\hline & & 5 & 5 & 2 \\
\hline & & 6 & 3 & 1 \\
\hline & Distribution & 1 & 1 & .2 \\
\hline & & 2 & 2 & .4 \\
\hline
\end{tabular}

Notes: $\quad$ 1. Activity numbers correspond to the activities shown in Figure 7. 2. All times are in days.

Figure 10 - Example Data For The Make To Order Environment 


\begin{tabular}{|c|c|c|c|c|c|}
\hline Production & Sequence & Sub-Cycle & Activity $^{(1)}$ & Act & Time $^{(2)}$ \\
\hline Environment & & & Number & $\begin{array}{l}\text { Mean } \\
\mathrm{E}(\mathrm{)}\end{array}$ & $\begin{array}{c}\text { Standard } \\
\text { Deviation, } \sigma()\end{array}$ \\
\hline ATO & S1 & Order & 1 & .5 & .2 \\
\hline & & Processing & 2 & 5 & 2 \\
\hline & & & 3 & 1 & .5 \\
\hline & & Design & 3 & 6 & 3 \\
\hline & & & 4 & 5 & 3 \\
\hline & & & 5 & 2 & .5 \\
\hline & & Supply & 4 & 1 & .2 \\
\hline & & Management & 6 & 15 & 8 \\
\hline & & Production & 1 & 3 & 1 \\
\hline & & & 4 & 1 & .2 \\
\hline & & & 5 & 5 & 2 \\
\hline & & Distribution & 2 & 1 & .2 \\
\hline & & & 3 & 2 & .4 \\
\hline & S2 & Order & none & & \\
\hline & & Processing & & & \\
\hline & & Design & 1 & 30 & 10 \\
\hline & & & 2 & 10 & 5 \\
\hline & & & 5 & & 3 \\
\hline & & Supply & 1 & 5 & 2 \\
\hline & & Management & 2 & 10 & 5 \\
\hline & & & 3 & 10 & 5 \\
\hline & & & 4 & 1 & .2 \\
\hline & & & 5 & 4 & 2 \\
\hline & & & 6 & 15 & 8 \\
\hline & & Production & 1 & 3 & 1 \\
\hline & & & 2 & 3 & 1 \\
\hline & & & 3 & 20 & 8 \\
\hline & & & 6 & 5 & 3 \\
\hline & & & 7 & 15 & 5 \\
\hline & & Distribution & none & & \\
\hline
\end{tabular}

Notes: $\quad$ 1. $\quad$ Activity numbers correspond to the activities shown in Figure 8.

2. All times are in days.

Figure 11 - Example Data For The Assemble To Order Environment 


\begin{tabular}{|c|c|c|c|c|c|}
\hline \multirow{2}{*}{$\begin{array}{l}\text { Production } \\
\text { Environment }\end{array}$} & \multirow[t]{2}{*}{ Sequence } & \multirow[t]{2}{*}{ Sub-Cycle } & \multirow{2}{*}{$\begin{array}{l}\text { Activity } \\
\text { Number }\end{array}$} & \multicolumn{2}{|c|}{ Activity Time ${ }^{(2)}$} \\
\hline & & & & $\begin{array}{l}\text { Mean } \\
\mathrm{E}(\mathrm{)}\end{array}$ & $\begin{array}{c}\text { Standard } \\
\text { Deviation, } \sigma()\end{array}$ \\
\hline \multirow[t]{7}{*}{ MTS } & \multirow[t]{7}{*}{ S1 } & Order & 1 & .5 & .2 \\
\hline & & Processing & 2 & 1.0 & .3 \\
\hline & & Design & none & & \\
\hline & & $\begin{array}{l}\text { Supply } \\
\text { Management }\end{array}$ & none & & \\
\hline & & Production & none & & \\
\hline & & Distribution & 2 & 1 & .2 \\
\hline & & & 3 & 2 & .4 \\
\hline \multirow[t]{18}{*}{. } & \multirow[t]{18}{*}{ S2 } & $\begin{array}{l}\text { Order } \\
\text { Processing }\end{array}$ & none & & \\
\hline & & Design & 1 & 40 & 10 \\
\hline & & & 2 & 20 & 5 \\
\hline & & & 3 & 15 & 5 \\
\hline & & Supply & 1 & 5 & 2 \\
\hline & & Management & 2 & 10 & 5 \\
\hline & & & 3 & 10 & 5 \\
\hline & & & 4 & 1 & .2 \\
\hline & & & 5 & 4 & 2 \\
\hline & & & 6 & 15 & 8 \\
\hline & & Production & 1 & 5 & 2 \\
\hline & & & 2 & 5 & 2 \\
\hline & & & 3 & 20 & 8 \\
\hline & & & 4 & 5 & 4 \\
\hline & & & 5 & 5 & 4 \\
\hline & & & 6 & 5 & 3 \\
\hline & & & 7 & 15 & 5 \\
\hline & & Distribution & 1 & 10 & 4 \\
\hline
\end{tabular}

Notes: $\quad$ 1. Activity numbers correspond to the activities shown in Figure 9.

2. All times are in days.

Figure 12 -- Example Data For The Make To Stock Environment 


\begin{tabular}{|c|c|c|c|c|c|}
\hline & & $\begin{array}{l}\text { Financial } \\
\text { Cycle Time, } \\
\text { FCT }\end{array}$ & $\begin{array}{l}\text { Customer } \\
\text { Cycle Time, } \\
\text { CCT }\end{array}$ & $\begin{array}{l}\text { Total Cycle } \\
\text { Time, TCT }\end{array}$ & $\begin{array}{l}\text { Total Time, } \\
\text { TT }\end{array}$ \\
\hline MTO & $\begin{array}{l}\mathrm{E}(\mathrm{)}) \\
\sigma() \\
\text { Activities in } \\
\text { decreasing } \\
\text { order of } \delta_{i}^{\mathrm{PM}}\end{array}$ & $\begin{array}{l}36 \text { days } \\
8.7 \text { days } \\
\text { 3, Prod'n } \\
\text { 4, Prod'n } \\
\ldots \\
\end{array}$ & 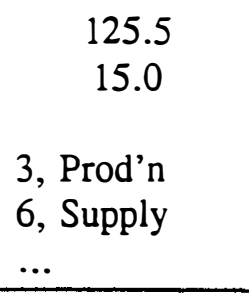 & 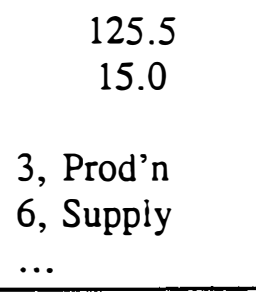 & $\begin{array}{r}125.5 \\
15.0 \\
\\
\text { 3, Prod'n } \\
6 \text {, Supply } \\
\text {.. } \\
\end{array}$ \\
\hline ATO & $\begin{array}{l}\mathrm{E}(\mathrm{)} \\
\sigma() \\
\text { Activities in } \\
\text { decreasing } \\
\text { order of } \delta_{i}^{\mathrm{PM}}\end{array}$ & $\begin{array}{l}\quad 58 \text { days } \\
10.3 \text { days } \\
\text { 3, Prod'n, S2 } \\
\text { 7, Prod'n, S2 } \\
\text {... }\end{array}$ & $\begin{array}{l}47.5 \\
9.6 \\
\\
\text { 6, Supply, S1 } \\
\text { 3, Design, S1 } \\
\text {.. } \\
\end{array}$ & $\begin{array}{l}153 \\
19.0 \\
\\
\text { 1, Design, S2 } \\
\text { 3, Prod'n, S2 } \\
\ldots \\
\end{array}$ & $\begin{array}{l}188.5 \\
21.2 \\
\\
\text { 1, Design,S2 } \\
\text { 3, Prod'n, S2 } \\
\text {... } \\
\end{array}$ \\
\hline MTS & $\begin{array}{l}\mathrm{E}() \\
\sigma() \\
\text { Activities in } \\
\text { decreasing } \\
\text { order of } \delta_{\mathrm{i}}^{\text {PM }}\end{array}$ & $\begin{array}{l}73 \text { days } \\
12.4 \text { days } \\
\text { 3, Prod'n, S2 } \\
\text { 7, Prod'n, S2 } \\
\text {... }\end{array}$ & $\begin{array}{l}4.5 \\
.6 \\
\text { 3, Dist'n, S1 } \\
\text { 2, Order, S1 } \\
\ldots\end{array}$ & $\begin{array}{l}193 \\
\begin{array}{l}20.6 \\
\text { 1, Design, S2 } \\
\text { 3, Prod'n, S2 } \\
\ldots\end{array}\end{array}$ & $\begin{array}{l}194.5 \\
20.6 \\
\text { 1, Design,S2 } \\
\text { 3, Prod'n, S2 } \\
\ldots\end{array}$ \\
\hline
\end{tabular}

Figure 13 - Identifying Activities For Cycle Time Reduction in Example 1 


\section{A Simple Markov Model}

Insight into cycle time management/reduction can also be gained by modelling the manufacturing cycle as a Markov chain. Among other things this permits dependencies between activity times to be accounted for.

\subsection{Make To Order, MTO, Environment}

The MTO environment was shown in Figure 7. The simplest Markov chain that can be used to model this environment is an absorbing Markov chain consisting of the following six states:

1. Order processing,

2. Design,

3. Supply management,

4. Production,

5. Distribution, and

6. Order completion.

This Markov chain and its transition probability matrix, $\mathrm{P}$, are shown in Figure 14 . The following assumptions underlie this Markov chain.

1. An order begins in state 1 and is complete when it reaches state 6 . State 6 is an absorbing state, and states 1 through 5 are transient states.

2. Upon leaving a state, an order may only move forward or back one state.

3. The transition probability, $p_{i j}$ from state $i$ to state $j$ is an estimate of the probability that an order that was in state $i$ in one time period will be in state $j$ in the next time period. The length of the time period is set so that the probability of more than one transition occurring in one time period is zero.

The transition probability matrix of an absorbing Markov chain can be written as

Transient states; Absorbing state;

$$
\mathrm{P}=\quad \text { Transient states; } s_{1}, s_{2}, \ldots, s_{5}
$$

Absorbing state; $s_{6}$

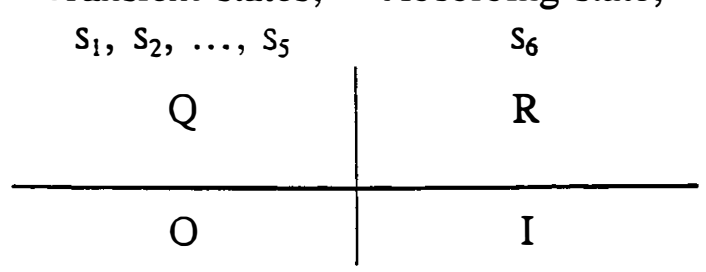




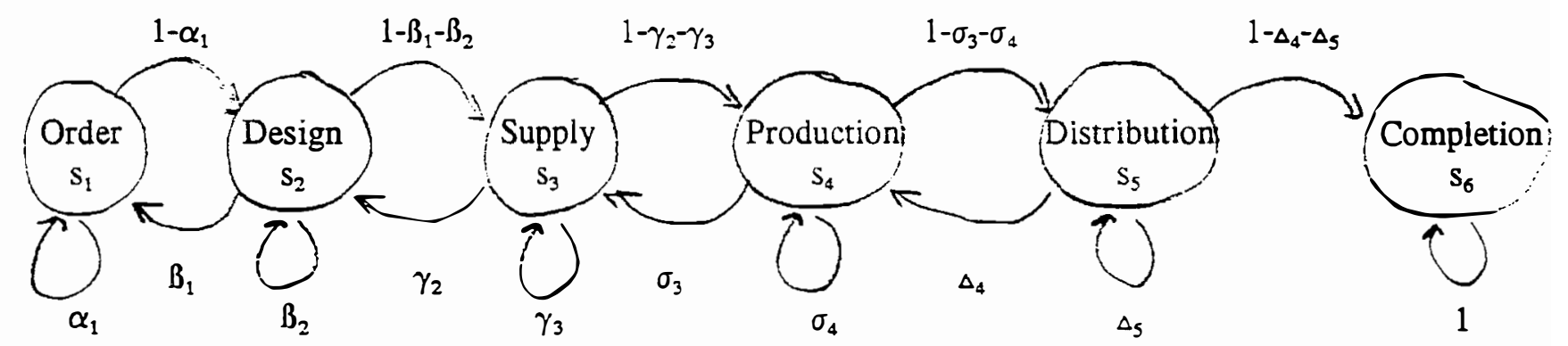

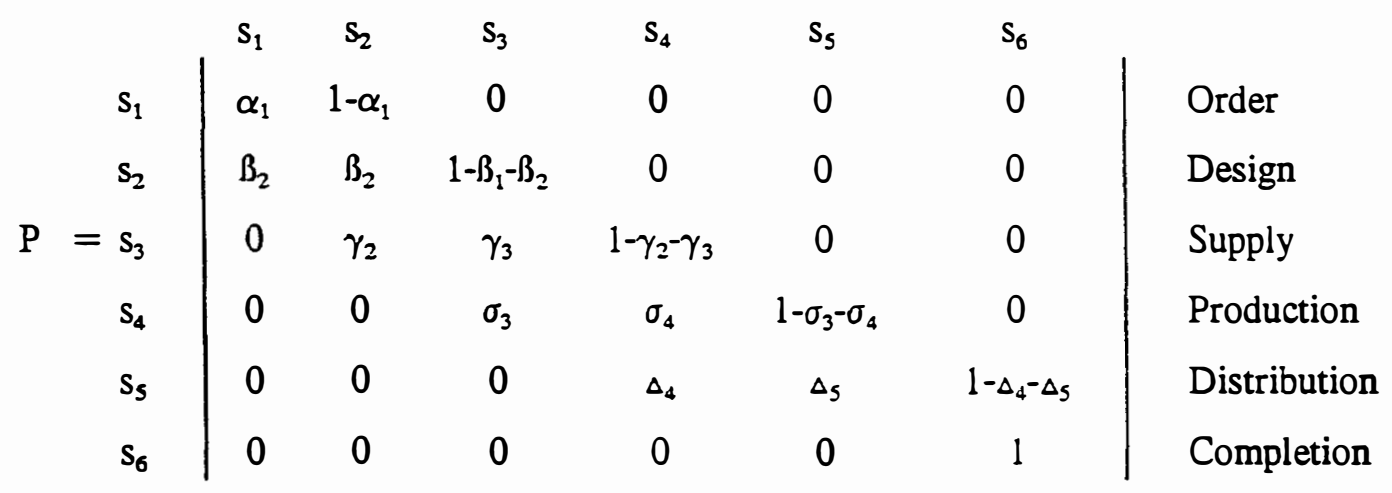

Figure 14 - Markov Chain and Transition Probability Matrix for MTO Environment 
from which the fundamental matrix, $\mathrm{N}$, can be determined.

$$
\mathbf{N}=(\mathbf{I}-\mathbf{Q})^{-1}
$$

(See Kemeny and Snell [1960] or Winston [pp. 928-936, 1991].) Each element, $\mathrm{n}_{\mathrm{ij}}$, of $\mathrm{N}$ is the expected number of periods that an order begining in state $\mathrm{i}$ will spend in state $\mathrm{j}$ prior to being absorbed. For the purposes of cycle time reduction, the elements of interest are those in the first row, $\mathrm{n}_{1 \mathrm{j}}$. The first state is the order processing sub-cycle (the sub-cycle in which all orders begin) and so these elements are the expected number of periods an order will spend in each sub-cycle before being completed. The expected total cycle time is

$$
E\left(T C T^{M T g}\right)=\sum_{j} n_{1 j}
$$

The variance of the number of periods spent in each sub-cycle is also of interest. Using Kemeny and Snell's notation [pp. 43-57, 1976] we define

$$
\mathbf{N}_{2}=\mathbf{N}\left(2 \mathbf{N}_{\text {diagonal }}-\mathbf{I}\right)-\mathbf{N}_{\text {sq }}
$$

where $\quad \mathrm{N}_{\text {diagonal }}$ - a matrix formed from $\mathrm{N}$ whose only non-zero elements are on the main diagonal,

I - Identity matrix, and

$\mathrm{N}_{\mathrm{sq}} \quad$ - is formed from $\mathrm{N}$ by squaring each element.

Each element, $\sigma_{\mathrm{ij}}{ }^{2}$, of $\mathrm{N}_{2}$ is the variance of the number of periods an order will spend in state $\mathrm{j}$ before being absorbed, when the order began in state $\mathrm{i}$. Since all orders begin in state 1 , the order processing sub-cycle, the variance of the total cycle time is

$$
\sigma^{2}\left(\mathrm{TCT}^{\mathrm{MTO}}\right)=\sum_{\mathrm{j}} \sigma_{1 \mathrm{j}}^{2}
$$


Here we make the simplifying assumption that the time spent in a state is independent of the time spent in other states. This assumption is relaxed in Appendix. We will see that this is a reasonable assumption.

The distribution of the number of periods an order spends in a particular state before being absorbed is not known. (It is interesting to note that when the process is a regular rather than absorbing Markov chain, similar expressions can be developed for the mean and variance of the number of periods each state is occupied during $\mathrm{n}$ periods, and this random variable has a normal distribution when $\mathrm{n}$ is large.)

Chebyshev's inequality can be used to find a simple upper bound on the total cycle time.

$$
\text { Probability }(\text { TCT } \geq E(T C T)+k \sigma(T C T)) \leq 1 / k^{2}
$$

This bound can be used to identify the sub-cycles that contribute the most to the cycle time.

\section{Example 2a}

Consider again the MTO environment faced by the company in Example la. Suppose that the manufacturing cycle time is modelled as an absorbing Markov chain with the following transition probability matrix:

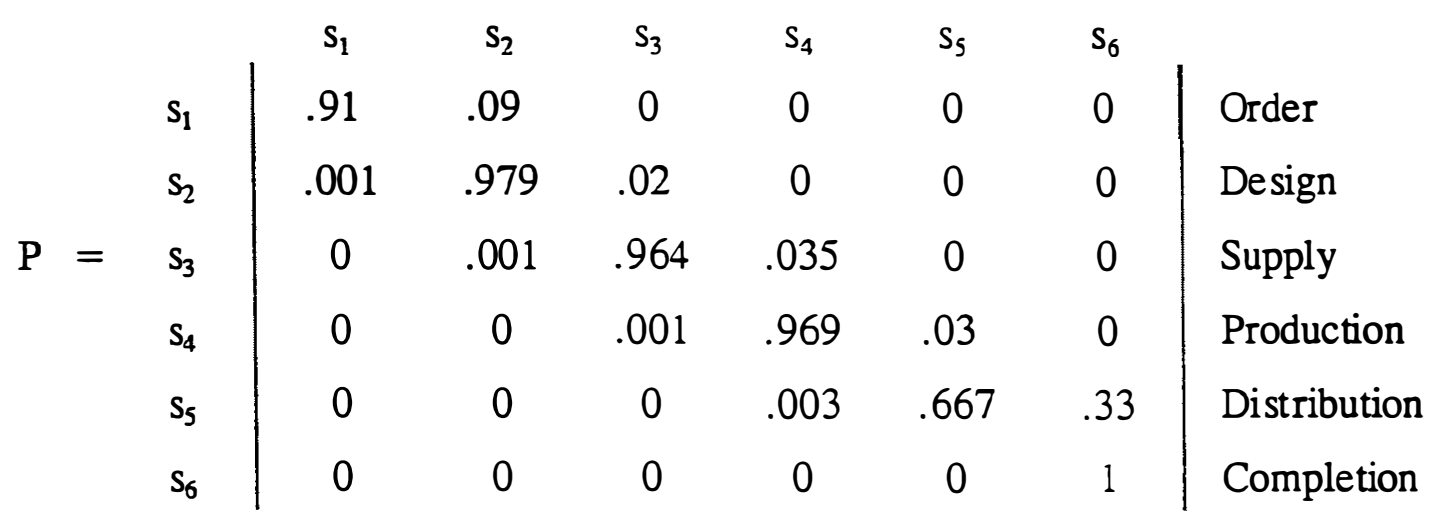


The time period is one day. That is, each element $\mathrm{p}_{\mathrm{ij}}$ of $\mathrm{P}$ is the probability that an order which is currently in state $s_{\mathrm{i}}$ will be in state $s_{\mathrm{j}}$ the next day.

Then I - Q, N $=(I-Q)^{-1}$ and $N_{2}=N\left(2 N_{\text {diagonal }}-I\right)-N_{s q}$ are:

$$
\begin{aligned}
& \mathrm{I}-\mathrm{Q}=\begin{array}{c|ccccc} 
& \mathrm{s}_{1} & \mathrm{~s}_{2} & \mathrm{~s}_{3} & \mathrm{~s}_{4} & \mathrm{~s}_{5} \\
\mathrm{~s}_{1} & .09 & -.09 & 0 & 0 & 0 \\
\mathrm{~s}_{2} & -.001 & .021 & -.02 & 0 & 0 \\
\mathrm{~s}_{3} & 0 & -.001 & .036 & -.035 & 0 \\
\mathrm{~s}_{4} & 0 & 0 & -.001 & .031 & -.03 \\
\mathrm{~s}_{5} & 0 & 0 & 0 & -.003 & .333
\end{array}
\end{aligned}
$$

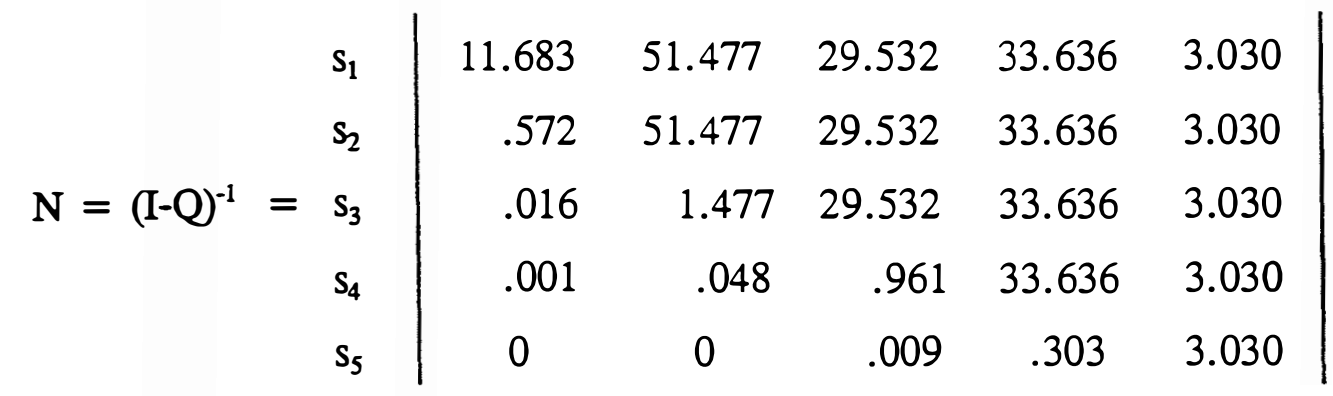

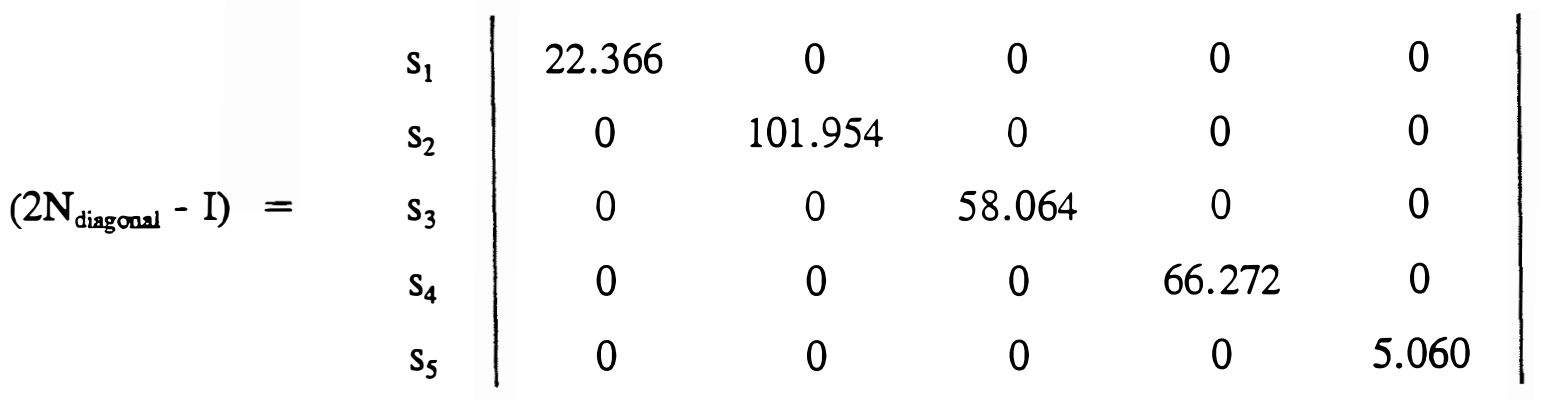

$$
\begin{aligned}
& \begin{array}{ll|rrrrr|} 
& \mathrm{s}_{1} & 261.305 & 5248.196 & 1714.80 & 2229.17 & 15.335 \\
& \mathrm{~s}_{2} & 12.793 & 5248.196 & 1714.80 & 2229.17 & 15.335 \\
& \mathrm{~s}_{3} & .367 & 150.546 & 1714.80 & 2229.17 & 15.335 \\
& \mathrm{~s}_{4} & .012 & 4.899 & 55.803 & 2229.17 & 15.335 \\
& \mathrm{~s}_{5} & 0 & .044 & .503 & 20.083 & 15.335
\end{array}
\end{aligned}
$$




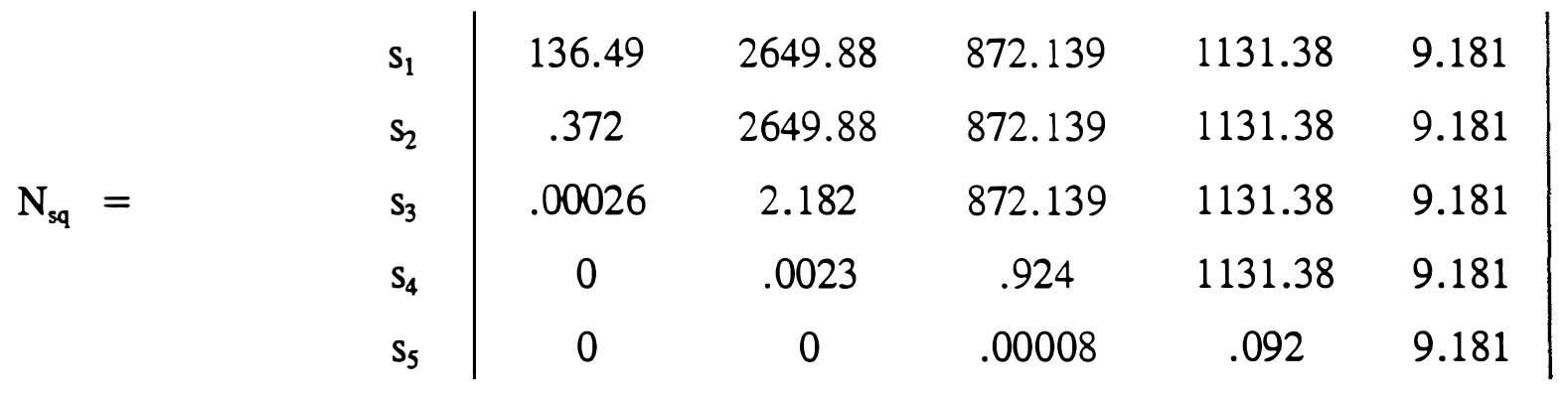

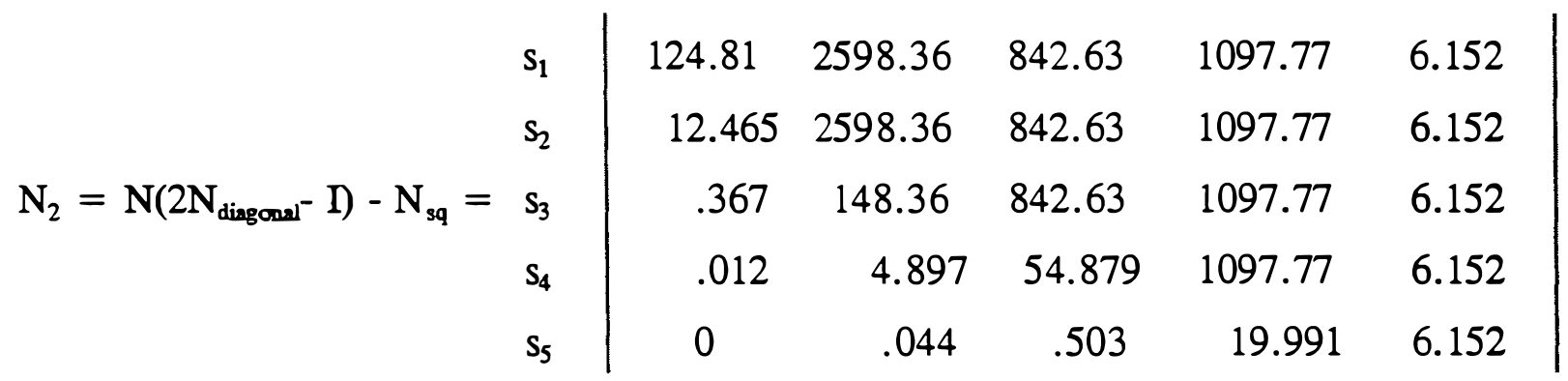

The expected value and standard deviation of the number of days that an order will spend in each state when it begins in state $s_{1}$ are:

\begin{tabular}{|c|c|c|c|}
\hline \multirow[t]{2}{*}{ State, $j$} & \multicolumn{3}{|c|}{ Number of Days } \\
\hline & $\begin{array}{l}\text { Expected Value } \\
\left(\mathrm{n}_{\mathrm{lj}} \text { from } \mathrm{N}\right)\end{array}$ & $\begin{array}{r}\text { Stand } \\
(\sqrt{0} \\
\end{array}$ & $\begin{array}{l}\text { Deviation } \\
\text { from } \mathrm{N}_{2} \text { ) }\end{array}$ \\
\hline $\begin{array}{l}s_{1} \\
s_{2} \\
s_{3} \\
s_{4} \\
s_{5}\end{array}$ & $\begin{array}{l}11.68 \text { days } \\
51.48 \\
29.53 \\
33.64 \\
3.03\end{array}$ & $\begin{array}{l}\sqrt{ } 124.81 \\
\sqrt{ } 2598.36 \\
\sqrt{842.63} \\
\sqrt{ } 1097.77 \\
\sqrt{ } 6.152\end{array}$ & $\begin{array}{l}=11.17 \\
=50.97 \\
=29.03 \\
=33.13 \\
=\quad 2.48\end{array}$ \\
\hline Total & 129.36 & $\sqrt{4669.72^{\circ}}$ & $=68.34$ \\
\hline
\end{tabular}

* For ease of computation we assume that the number of days in a state are independent. If this assumption is dropped (Appendix 1) the variance is 4827.7.

The expected total cycle time is 129.4 days. This is also the expected customer cycle time. (See Figure 7.) The expected financial cycle time is 33.7 days (consisting of states, or sub-cycles, 4 and 5). Notice that the expected times from this Markov chain model are 
approximately the same as the expected times for the simple stochastic model in section 3. (See Figure 13.)

Equation 11 can provide an upper bound on the total cycle time. If $\mathrm{k}=3$, then

$$
\begin{aligned}
& \mathrm{P}(\mathrm{TCT} \geq 129.36+3 \times 68.34) \leq 1 / 3^{2} \\
\Rightarrow & \mathrm{P}(\mathrm{TCT} \geq 334.38) \leq .11 .
\end{aligned}
$$

The probability that the total cycle time will exceed 334.4 days is less than $11 \%$. This approach is used in Figure 15 to identify the sub-cycles that contribute most to the total cycle time. Notice that eliminating sub-cycle 2 would most improve the total cycle time. Hence this subcycle has the highest priority for improvement activities. If the goal is to reduce financial cycle time, then improvement activities would focus on sub-cycle 4 .

It is possible to simplify equation 11 (see ${ }_{n}^{\text {th }}$ Appendix) which makes the ranking procedure even easier.

\section{Applying the Simple Markov Model to Sub-Cycles}

A Markov chain model could be applied in an similar way to each individual sub-cycle. The states in this Markov chain are the activities that comprise the sub-cycle plus a state representing completion of the sub-cycle. The last state is an absorbing state, the other states are transient states and the chain is an absorbing Markov chain.

For example, the absorbing Markov chain for the supply management sub-cycle is shown in Figure 16. Analysis of this model would help identify the activities where cycle time reduction is needed most.

\subsection{Assemble to Order, ATO, Environment}

A simple ATO environment was described in section 2.1. (See Figure 8.) The activities that comprise total cycle time in this environment can be arranged into two sequences. Sequence S1 consists of those activities that occur as a direct result of a specific customer order. 


\begin{tabular}{c|ccc}
$\begin{array}{c}\text { Sub-Cycle, } \mathrm{s}_{\mathrm{j}}, \\
\text { to be dropped }\end{array}$ & $\begin{array}{c}\text { Expected Value } \\
\mathrm{E}\left(\mathrm{TCT}^{\mathrm{R}}\right)\end{array}$ & $\begin{array}{c}\text { Remaining Total Cycle Time, } \\
\text { Standard Deviation } \\
\sigma\left(\mathrm{TCT}^{\mathrm{R}}\right)\end{array}$ & $\begin{array}{c}\text { Realization, } \mathrm{X} \\
\left.\text { where P(TCT }^{\mathrm{R}} \geq \mathrm{X}\right) \leq .11^{(2)}\end{array}$ \\
\hline none & 129.36 days & 68.34 days & 334.38 days \\
1 & $117.68^{(1)}$ & $67.42^{(1)}$ & 319.94 \\
2 & 77.88 & 45.51 & 214.41 \\
3 & 99.83 & 61.86 & 285.41 \\
4 & 95.72 & 59.77 & 275.03 \\
5 & 126.33 & 68.29 & 331.20
\end{tabular}

Notes 1) $\mathrm{E}\left(\mathrm{TCT}^{\mathrm{R}}\right)=\mathrm{E}(\mathrm{TCT})-\mathrm{n}_{1 \mathrm{j}}=129.36-11.68=117.68$
$\sigma\left(\mathrm{TCT}^{\mathrm{R}}\right)=\sqrt{ }\left(\sigma^{2}(\mathrm{TCT})-\sigma_{1 \mathrm{j}}^{2}\right)=\sqrt{ }(4669.72-124.81)=67.42$

2) Equation 11 with $\mathrm{k}=3$ and $\mathrm{X}=\mathrm{E}\left(\mathrm{TCT}^{\mathrm{R}}\right)+\mathrm{k} \sigma\left(\mathrm{TCT}^{\mathrm{R}}\right)$.

Figure 15 - Identifying Sub-Cvcle Contribution to Total Cvcle Time in Example 2a 


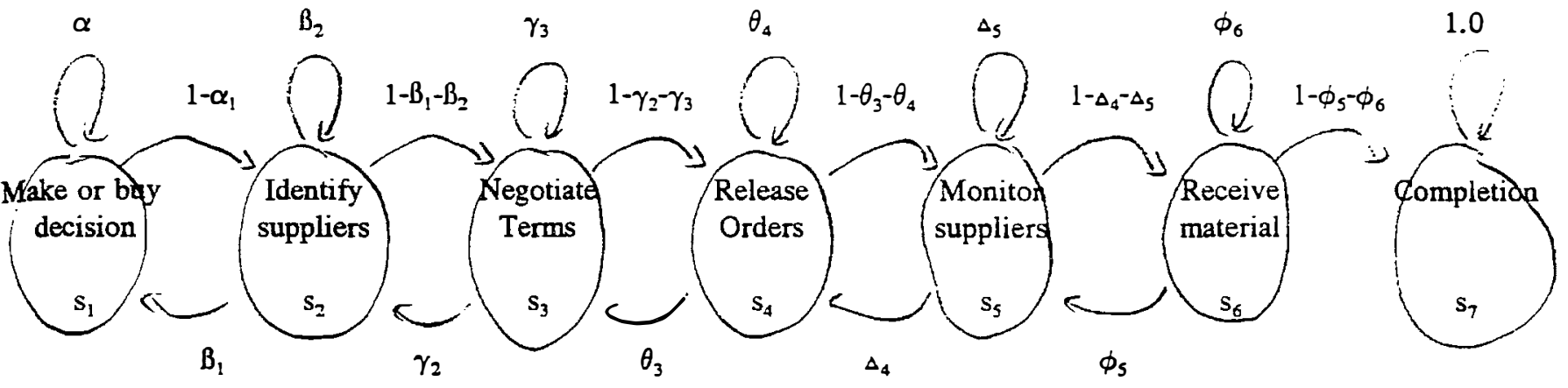

Figure 16 -- Markov Chain for Supply Management Sub-Cycle in the MTO Environment 
S1 is modeled by an absorbing Markov chain similar to that for the MTO environment. An additional state 0 , to represent the system when no order is present, has been added to $S 1$. This allows component part production to begin prior to the arrival of an order. The activities in sequence $S 2$, are those related to the design and production of standard components which are inventoried for later use in a customer order. The Markov chain representation of both ATO sequences is shown in Figure 17.

The ATO case is complicated by the fact that each customer order for a product requires many standard components to be combined into one product. This requires one S1 sequence for the product and many S2 sequences -- one for each component. Improving the cycle time in an ATO environment involves reducing cycle times for sequence S1, each S2 sequence, and cycle times caused by interactions between the sequences.

Beginning with the simplest case, the assumption may be made that there are always sufficient component parts in inventory to fill customer orders. This eliminates the need for considering the S1 and S2 sequences simultaneously. Rather each sequence is analyzed separately, as in section 4.1 for the MTO environment. Although such a simpification provides insights into where improvements can be made, it overlooks possible delays caused by Tteractions between the sequences.

The next level of analysis, modelling parts-orders interactions, includes the following assumptions:

1. A customer order may not progress beyond state 3 -- final assembly supply management -- unless all component parts are already in inventory -- state 10 for the S2 sequence.

2. All components are used in a final product on the basis of one unit of each component 
Sequence S1: Customer Order and Final Assembly

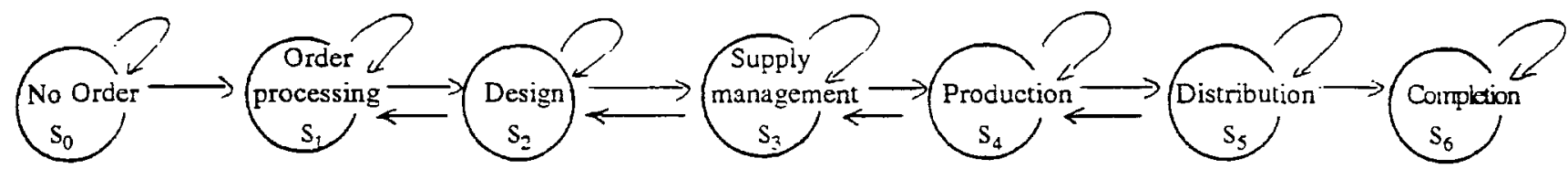

Sequence S2: Standard Components

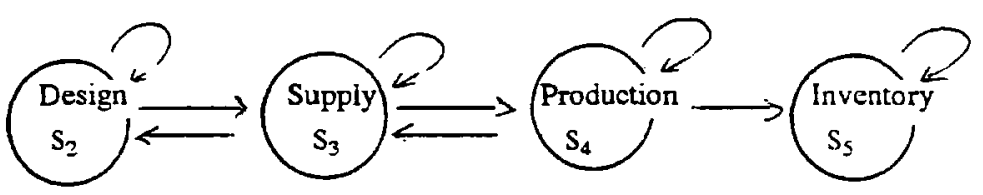

Sequence S1 and S2

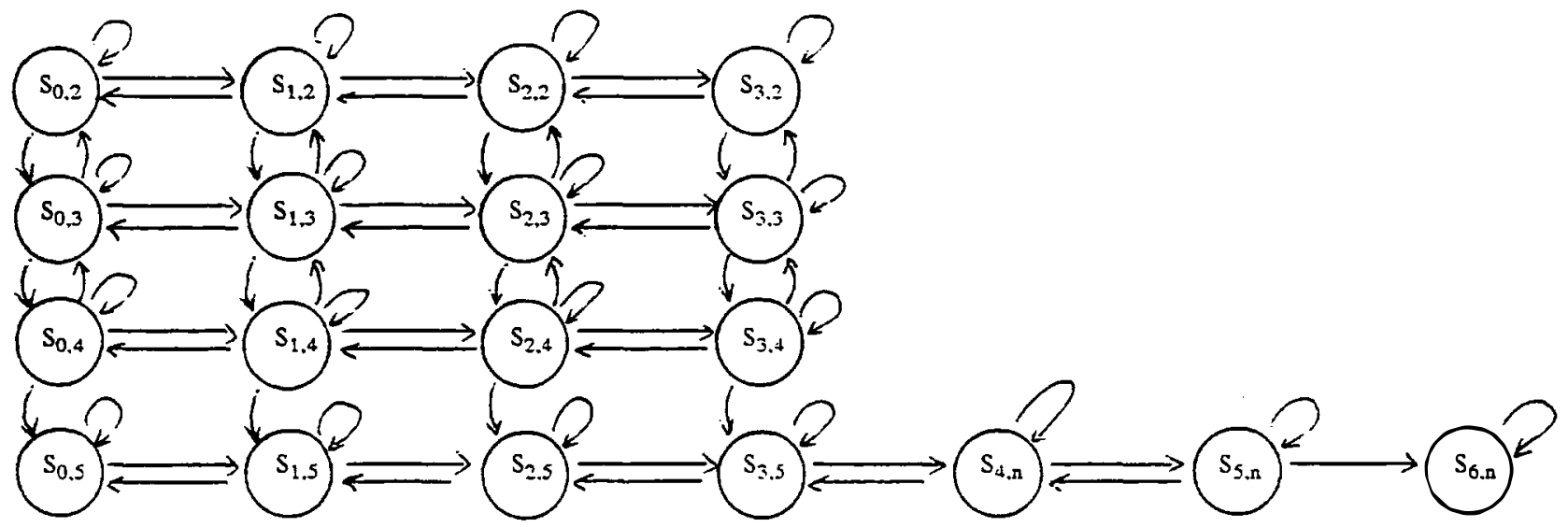

Note: In $\mathrm{s}_{\mathrm{i}, \mathrm{j}} \mathrm{i}$ and $\mathrm{j}$ denote the cycles in sequences $\mathrm{S} 1$ and $\mathrm{S} 2$ respectively.

Figure 17 Markov Chain Models for an ATO Environment 
part per final product order.

As this is an absorbing Markov chain, equations 7, 8, 9 and 11 hold.

The process of completing an order for a final product $\mathrm{p}$, an S1 sequence, will initiate up to $n(p)$ orders for component parts. There will be $n(p)$ S2 sequences and one S1 sequence to be considered. Consequently, there will be $4^{\mathrm{n}(\mathrm{p})+1}+3$ possible states in the Markov chain model. Figure 17 shows the Markov chain when $n(p)=1$. Because the size of the problem increases exponentially with $\mathrm{n}(\mathrm{p})$, it is necessary to limit the number of components considered. This could be accomplished by considering only a small number of critical components or forming groups of components. The following illustrative problem considers the case of one product with one critical component.

\section{Example 2b.}

In what follows three Markov chain models are developed and analyzed for a company operating in an ATO environment. These are the S1 sequence model, S2 sequence model, and the S1 and S2 sequence model. For the sake of clarity only one critical component is considered.

\section{S1 Sequence: Customer Orders}

The Markov chain and computations for this model are shown in part 1 of Figure 18. Note that that it is not necessary to include state $s_{0}$, no order in the process, in this model.

\begin{tabular}{c|cc} 
State, $\mathrm{s}_{i}$ & Expected Value & Standard Deviation \\
\hline $\mathrm{s}_{1}$ & 7.80 & 7.28 \\
$\mathrm{~s}_{2}$ & 16.94 & 16.43 \\
$\mathrm{~s}_{3}$ & 18.58 & 18.07 \\
$\mathrm{~s}_{4}$ & 11.49 & 10.98 \\
$\mathrm{~s}_{5}$ & 3.45 & 2.91
\end{tabular}




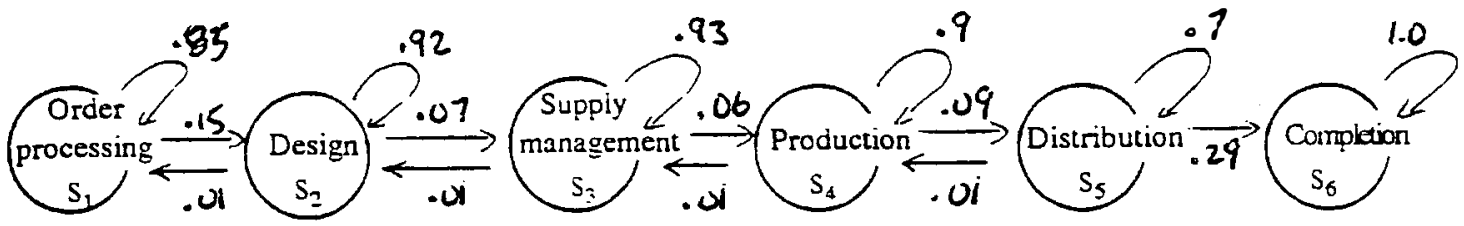

1
2
3
5
6 $\left[\begin{array}{rrrrrr}0.85 & 0.15 & 0 & 0 & 0 & 0 \\ 0.01 & 0.92 & 0.07 & 0 & 0 & 0 \\ 0 & 0.01 & 0.93 & 0.06 & 0 & 0 \\ 0 & 0 & 0.01 & 0.9 & 0.09 & 0 \\ 0 & 0 & 0 & 0.01 & 0.7 & 0.29 \\ 0 & 0 & 0 & 0 & 0 & 1\end{array}\right]$

1
3
5 $\left[\begin{array}{rrrrr}0.85 & 0.15 & 3 & 4 & 5 \\ 0.01 & 0.92 & 0.07 & 0 & 0 \\ 0 & 0.01 & 0.93 & 0.06 & 0 \\ 0 & 0 & 0.01 & 0.9 & 0.09 \\ 0 & 0 & 0 & 0.01 & 0.7\end{array}\right]$

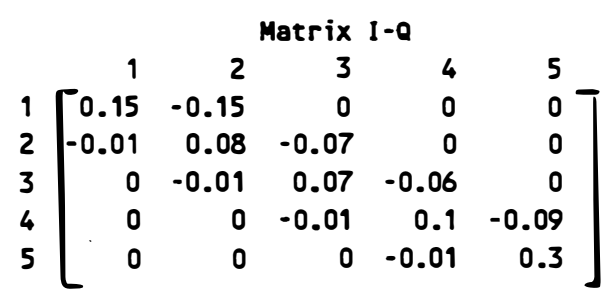

(2Ndiag- I )
1
3
4
5 $\left[\begin{array}{ccccc}14.592 & 0 & 3 & 4 & 5 \\ 0 & 32.881 & 0 & 0 & 0 \\ 0 & 0 & 36.165 & 0 & 0 \\ 0 & 0 & 0 & 21.989 & 0 \\ 0 & 0 & 0 & 0 & 5.8966\end{array}\right]$

$\begin{array}{lllll}\text { Nsq } & 2 & 3 & 4 & 5\end{array}$

$1\left[\begin{array}{lrrrr}60.778 & 286.98 & 345.3 & 132.12 & 11.891\end{array}\right.$

$2 \quad 1.2754 \quad 286.98 \quad 345.3 \quad 132.12 \quad 11.891$

$30.0313 \quad 7.047 \quad 345.3 \quad 132.1211 .891$

$40.0003 \quad 0.07493 .6699132 .1211 .891$

$5[3.7 E-078.3 E-050.00410 .146811 .891]$

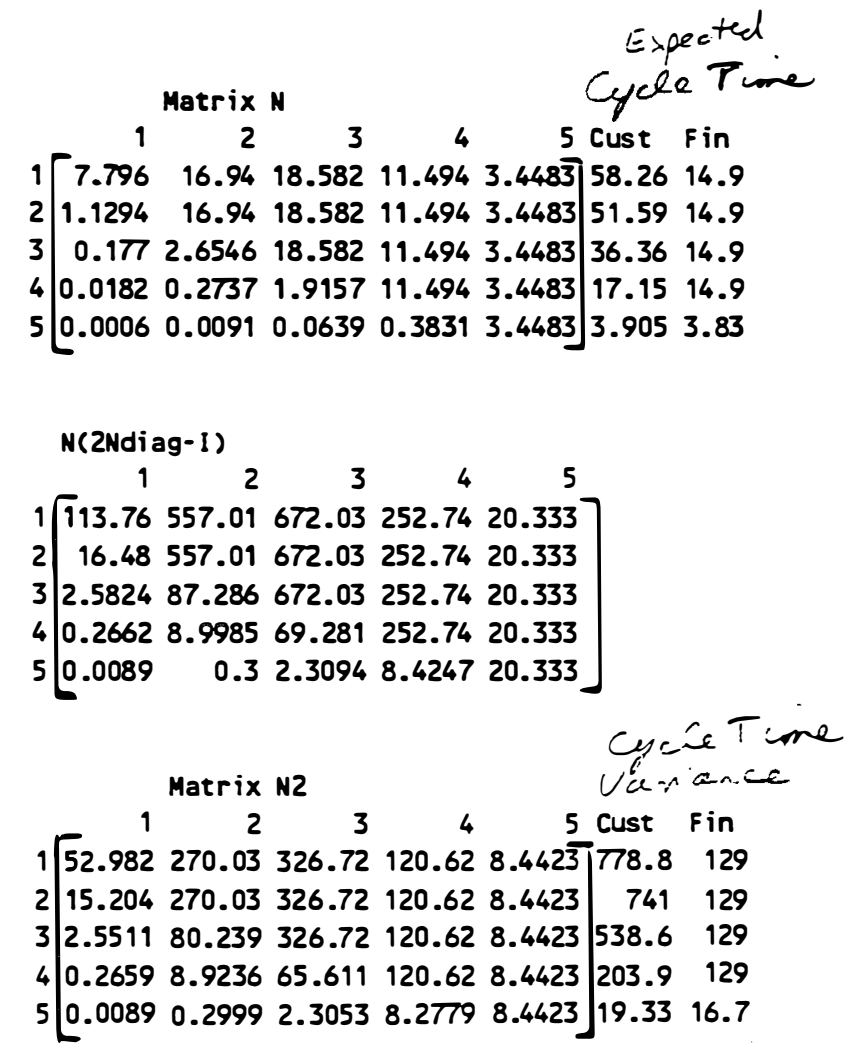

Figure 18 Part 1: S1 Sequence Markov Chain Model for Example 2b 
For this sequence cycle time reduction efforts should concentrate on the supply subcycle,

state $s_{3}$, as it contributes the most to the cycle time.

Sequence S2: One Critical Standard Component

The Markov chain and computations for this model are shown in part 2 of Figure 18.

$\begin{array}{ccc}\text { State, } s_{\mathrm{j}} & \text { Expected Value } & \text { Standard Deviation } \\ \mathrm{s}_{2} & 75 & 74.5 \\ \mathrm{~s}_{3} & 50 & 49.5 \\ \mathrm{~s}_{4} & 50 & 49.5\end{array}$

Cycle time improvement efforts should focus on the design of standard components subcycle, state $s_{2}$ in this sequence.

\section{Sequences S1 and S2}

If both sequences are considered simultaneously the states are defined according to the sub-cycle in sequence $S 1$ and the sub-cycle in sequence $S 2$ (as shown in Figure 17). Suppose that the following transition probability matrix, $\mathrm{P}$, accurately models the manufacturing cycle. Each element $\mathrm{p}_{\mathrm{ij}, \mathrm{uv}}$ in $\mathrm{P}$ is the probability that an order which is currently in state $s_{\mathrm{ij}}$ will be in state $\mathrm{s}_{\mathrm{uv}}$ the next day.

\begin{tabular}{|c|c|c|c|c|c|c|c|c|c|c|c|c|c|c|c|c|c|c|c|}
\hline $3: j$ & 0,2 & 0,3 & 0,4 & 0,5 & 1,2 & 1,3 & 1,4 & 1,5 & 2,2 & 2,3 & 2,4 & 2,5 & 3,2 & 3,3 & 3,4 & 3,5 & $4, n$ & $5, n$ & $6, n$ \\
\hline 0,2 & 0.882 & 0.018 & 0 & 0 & 0.098 & 0.002 & 0 & 0 & 0 & 0 & 0 & 0 & 0 & 0 & 0 & 0 & 0 & 0 & 0 \\
\hline 0,3 & 0.009 & 0.873 & 0.018 & 0 & 0.001 & 0.097 & 0.002 & 0 & 0 & 0 & 0 & 0 & 0 & 0 & 0 & 0 & 0 & 0 & 0 \\
\hline 0,4 & 0 & 0.009 & 0.846 & 0.045 & 0 & 0.001 & 0.094 & 0.005 & 0 & 0 & 0 & 0 & 0 & 0 & 0 & 0 & 0 & 0 & 0 \\
\hline 0,5 & 0 & 0 & 0 & 0.9 & 0 & 0 & 0 & 0.1 & 0 & 0 & 0 & 0 & 0 & 0 & 0 & 0 & 0 & 0 & 0 \\
\hline 1,2 & 0 & 0 & 0 & 0 & 0.833 & 0.017 & 0 & 0 & 0.147 & 0.003 & 0 & 0 & 0 & 0 & 0 & 0 & 0 & 0 & 0 \\
\hline 1,3 & 0 & 0 & 0 & 0 & 0.009 & 0.825 & 0.017 & 0 & 0.002 & 0.146 & 0.003 & 0 & 0 & 0 & 0 & 0 & 0 & 0 & 0 \\
\hline 1,4 & 0 & 0 & 0 & 0 & 0 & 0.009 & 0.799 & 0.0425 & 0 & 0.002 & 0.141 & 0.0075 & 0 & 0 & 0 & 0 & 0 & 0 & 0 \\
\hline 1,5 & 0 & 0 & 0 & 0 & 0 & 0 & 0 & 0.85 & 0 & 0 & 0 & 0.15 & 0 & 0 & 0 & 0 & 0 & 0 & 0 \\
\hline 2,2 & 0 & 0 & 0 & 0 & 0.01 & 0.000 & 0 & 0 & 0.902 & 0.018 & 0 & 0 & 0.0686 & 0.0014 & 0 & 0 & 0 & 0 & 0 \\
\hline 2,3 & 0 & 0 & 0 & 0 & 0.000 & 0.01 & 0.000 & 0 & 0.009 & 0.892 & 0.018 & 0 & 0.0007 & 0.0679 & 0.001 & 0 & 0 & 0 & 0 \\
\hline 2,4 & 0 & 0 & 0 & 0 & 0 & 0.000 & 0.009 & 0.0005 & 0 & 0.009 & 0.865 & 0.046 & 0 & 0.0007 & 0.066 & 0.004 & 0 & 0 & 0 \\
\hline 2,5 & 0 & 0 & 0 & 0 & 0 & 0 & 0 & 0.01 & 0 & 0 & 0 & 0.92 & 0 & 0 & 0 & 0.07 & 0 & 0 & 0 \\
\hline 3,2 & 0 & 0 & 0 & 0 & 0 & 0 & 0 & 0 & 0.01 & 0.000 & 0 & 0 & 0.9696 & 0.0198 & 0 & 0 & 0 & 0 & 0 \\
\hline 3,3 & 0 & 0 & 0 & 0 & 0 & 0 & 0 & 0 & 0 & 0.005 & 0 & 0 & 0.005 & 0.98 & 0.01 & 0 & 0 & 0 & 0 \\
\hline 3,4 & 0 & 0 & 0 & 0 & 0 & 0 & 0 & 0 & 0 & 0.000 & 0.01 & 0.0005 & 0 & 0.0099 & 0.93 & 0.049 & 0 & 0 & 0 \\
\hline 3,5 & 0 & 0 & 0 & 0 & 0 & 0 & 0 & 0 & 0 & 0 & 0 & 0.01 & 0 & 0 & 0 & 0.93 & 0.06 & 0 & 0 \\
\hline $4, n$ & 0 & 0 & 0 & 0 & 0 & 0 & 0 & 0 & 0 & 0 & 0 & 0 & 0 & 0 & 0 & 0.01 & 0.9 & 0.09 & 0 \\
\hline $5, n$ & 0 & 0 & 0 & 0 & 0 & 0 & 0 & 0 & 0 & 0 & 0 & 0 & 0 & 0 & 0 & 0 & 0.01 & 0.7 & 0.29 \\
\hline $6, n$ & 0 & 0 & 0 & 0 & 0 & 0 & 0 & 0 & 0 & 0 & 0 & 0 & 0 & 0 & 0 & 0 & 0 & 0 & 1 \\
\hline
\end{tabular}




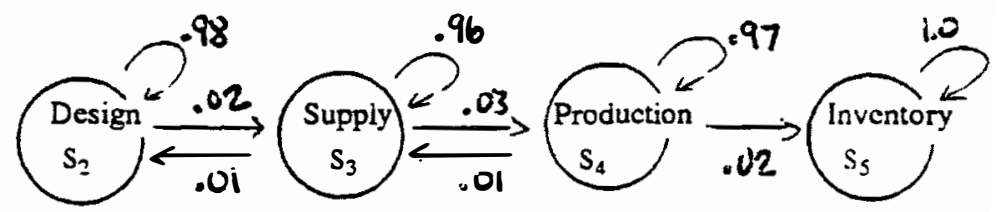

Matrix P

2
3
4
5 $\left[\begin{array}{rrrr}2 & 3 & 4 & 5 \\ 0.98 & 0.02 & 0 & 0 \\ 0 & 0.96 & 0.03 & 0 \\ 0 & 0 & 0 & 1\end{array}\right]$

Matrix N

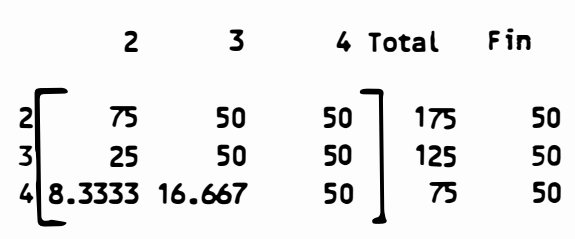

Nsq

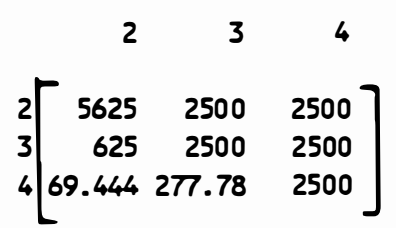

a

2
3 $\left[\begin{array}{rrr}2 & 3 & 4 \\ 0.98 & 0.02 & 0 \\ 0.01 & 0.96 & 0.03 \\ 0 & 0.01 & 0.97\end{array}\right]$

(2Ndiag-I)

$\left.\begin{array}{rrrr}2 & 3 & 4 \\ 3 & 2 & & \\ 149 & 0 & 0 \\ 0 & 99 & 0 \\ 0 & 0 & 99\end{array}\right]$

N2

$\left.\begin{array}{rrr}2 & 3 & 4 \\ 3 & \\ 3 & & \\ 5550 & 2450 & 2450 \\ 3100 & 2450 & 2450 \\ 1172.2 & 1372.2 & 2450\end{array}\right]$

Figure 18 (continued) Part 2: S2 Sequence Markov Chain Model for Example 2b 
Matices $\mathrm{N}$ and $\mathrm{N}_{2}$ are calculated as before. The fundamental matrix $\mathrm{N}$ shows the expected numer of periods spent in each state, given a particular initial state. The variance of the time spent in each state is given in matrix N2.

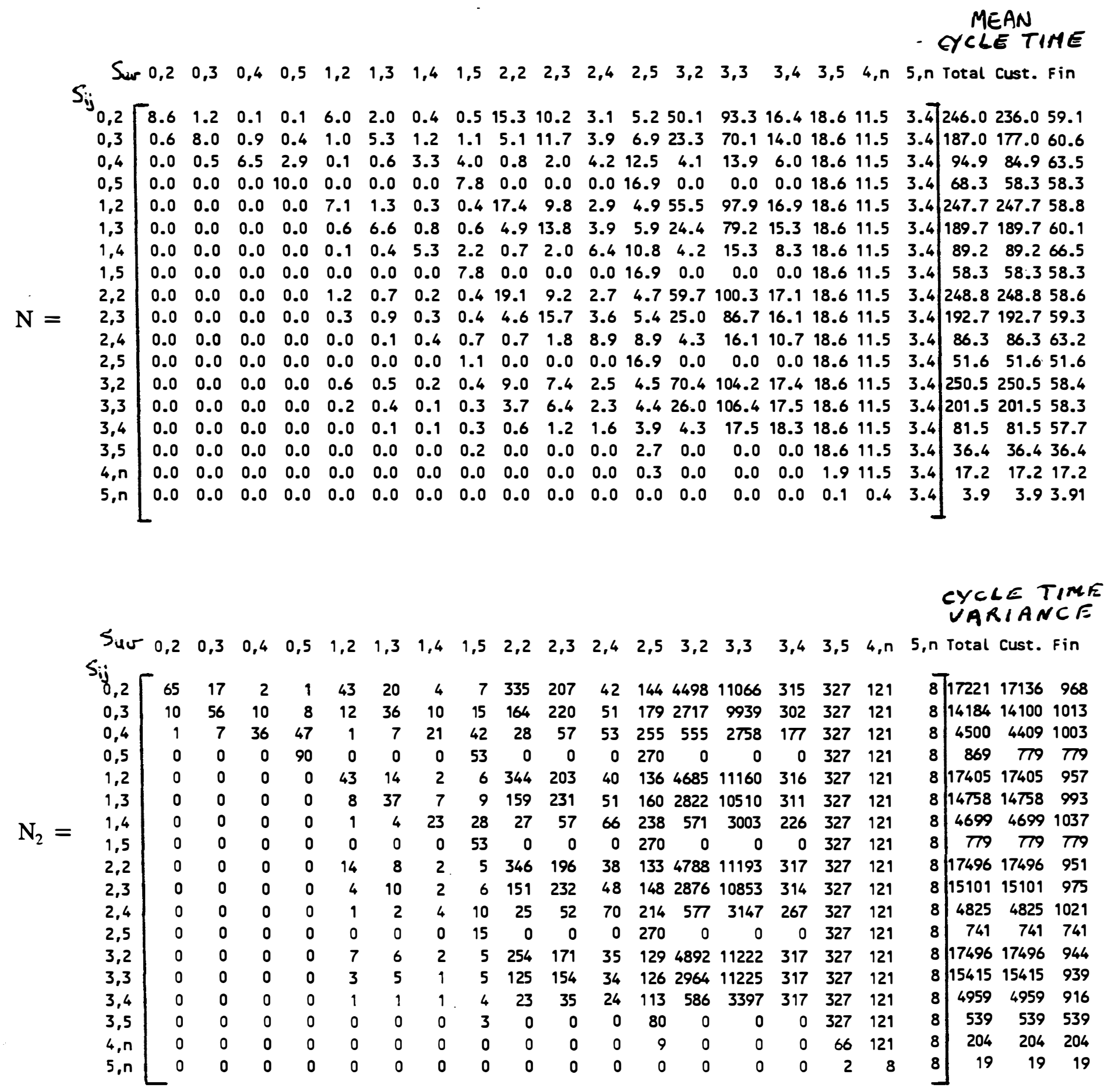


The performance measures -- financial cycle time, customer cycle time, total cycle time, and total time -- can now be calculated. Notice that cycle time depends on the initial state. The initial states of interest are states $s_{1 j}$, representing the arrival of new orders, and state $s_{0,2}$, the commencement of a component parts order prior to the arrival of a customer order.

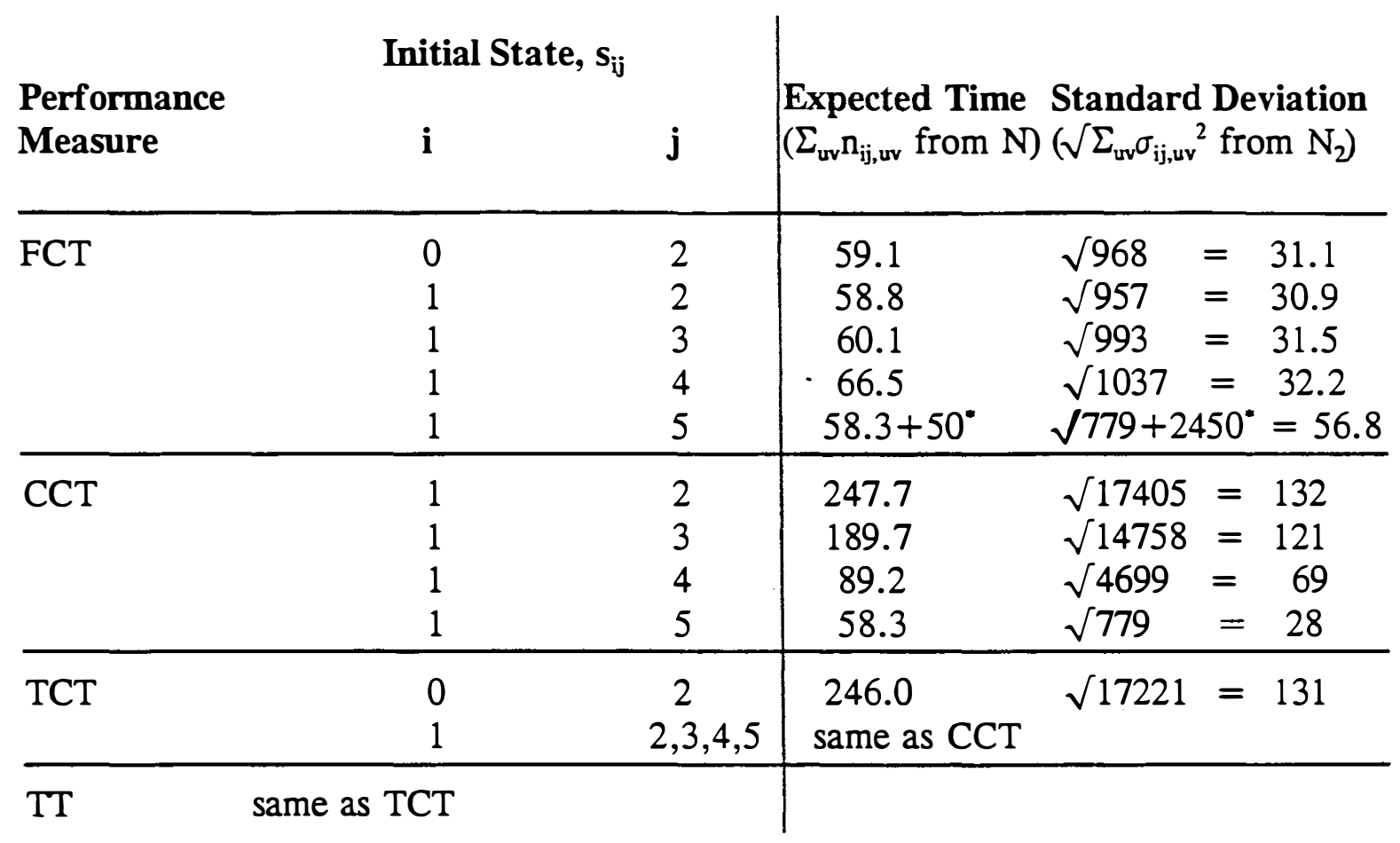

${ }^{*} \mathrm{n}_{24}$ and $\sigma_{24}{ }^{2}$ from Part 2 of Figure 18.

Notice that the expected times from this Markov chain model are approximately the same as the expected times for the simple stochastic model in section 3, if it is assumed that parts are always in stock. (See Figure 13.) This model offers the advantage of allowing the tradeoff between financial and customer cycle times to be evaluated. For example, if the component part production and inventory is included in FCT, then an additional 50 days (see calculations fro sequence S2) must be added to the FCT to account for financial cycle time prior to order arrival. Timing parts production so that component parts are either in production or inventory 
(states 4 and 5 in sequence $S_{2}$ ) when a customer order arrives yields the following tradeoff.

$\begin{array}{clr}\text { Initial State } & \text { FCT } & \text { CTC } \\ \mathrm{s}_{1,4} & 66.5 & 89.2 \\ \mathrm{~s}_{1,5} & 108.3 & 58.3\end{array}$

The basic choice is between timing parts production so that the expected order arrival date coincides with the expected arrival of the component parts in production to minimize financial cycle time, or the expected order arrival date coincides with the arrival of parts to inventory to minimize customer cycle time. Enhancements to the model would facilitate more precise timing of parts production so that financial cycle time could be reduced without overly increasing customer cycle time.

Depending on which performance measure is the most important, the sub-cycles that represents the largest elements of the cycle time can be identified and targeted for reduction. Suppose that the financial cycle time, FCT, was the most important performance measure in example $2 \mathrm{~b}$. Component parts production would be timed so that order arrival would coincide with the expected arrival of the component parts at the production sub-cycle (the process would begin in state $s_{1,4}$ ). The next task is to identify the sub-cycle to be targetted for cycle time reduction. In this case it is state $s_{3,5}$-- components waiting in inventory while the customer order is in the supply sub-cycle. Improvements in FCT could be made by better coordination of the two sequences. States $s_{1,4}, s_{2,4}$ and $s_{3,4}$ together contribute a total of 20 days to the expected FCT. This could be improved by concentrating on improving component parts production. If the performance measure of interest is TCT, finding the maximum value for $\Sigma_{\mathrm{k}=1}{ }^{\mathrm{m}} \mathrm{n}_{0, \mathrm{k}}+\sum_{\mathrm{j}=1}{ }^{\mathrm{m}+1} \mathrm{n}_{\mathrm{i}, \mathrm{j}}$, for $\mathrm{i}=1,2,3$ and $\mathrm{m}=$ initial S2 state at order arrival, would reveal which sub-cycle contributes the most to the TCT. 


\section{Applying the Simple Markov Model to Sub-Cycles}

A Markov chain model can be applied to each sub-cycle of the manufacturing cycle for the purpose of identifying those activities in the sub-cycle that contribute most to the cycle time. The Markov chain would be similar to that discussed in section 4.1 and shown in Figure 16.

\subsection{Make to Stock, MTS, Environment}

The MTS environment was described in section 2.1. (See Figure 9.) The analysis of this environment is quite similar to the analysis of the ATO environment (section 4.2) when the cycle is modelled as a Markov chain. This is because in both environments the tasks involved may be modelled by two sequences of activities, S1 and S2. While the sequences are different, the nature of the sequences and their interaction is similar. The Markov chain modelling both sequences simultaneously consists of ten states:

\begin{tabular}{|c|c|c|}
\hline State & Sequence S1 & Sequence S2 \\
\hline$s_{0,2}$ & No order & Design \\
\hline$s_{0,3}$ & No order & Supply \\
\hline$s_{0,4}$ & No order & Production \\
\hline$s_{0,5}$ & No order & Inventory \\
\hline$s_{1,2}$ & Order processing & Design \\
\hline$s_{1,3}$ & Order processing & Supply \\
\hline$s_{1,4}$ & Order processing & Production \\
\hline$s_{1,5}$ & Order processing & Inventory \\
\hline$S_{5, n}$ & Distribution & \\
\hline$S_{6, n}$ & Order completion & \\
\hline
\end{tabular}

Assumptions like those made for the ATO environment in section 4.2 underlie this model. The states that comprise the four performance measures are:

\begin{tabular}{l|l} 
Performance Measure & States \\
\hline FCT, financial cycle time & $\mathrm{s}_{04}, \mathrm{~s}_{05}, \mathrm{~s}_{14}, \mathrm{~s}_{15}, \mathrm{~s}_{5 \mathrm{n}}$ \\
CCT, customer cycle time & $\mathrm{s}_{12}$ to $\mathrm{s}_{5_{\mathrm{n}}}$ \\
TCT, total cycle time & $\mathrm{s}_{02}$ to $\mathrm{s}_{5 \mathrm{n}}$ \\
TT, total time & same as TT
\end{tabular}


Example 2c

Consider again the MTS environment faced by the company in Example 1c. Suppose that the following transition probability matrix accurately models the manufacturing cycle.

$$
\begin{aligned}
& \text { Suv } \\
& P=
\end{aligned}
$$

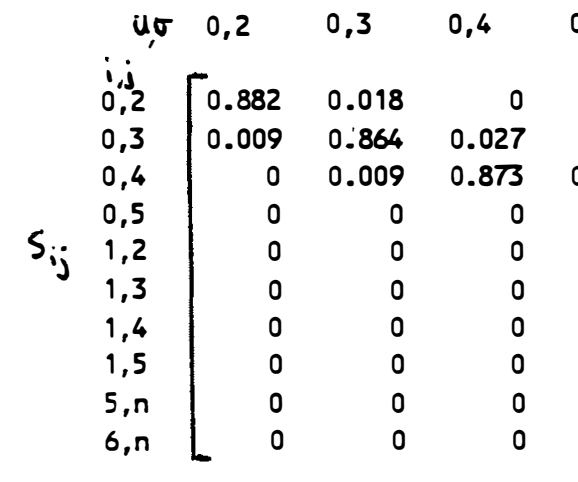

$$
\begin{aligned}
& 0,3 \quad 0,4 \\
& 0,5 \quad 1,2 \\
& 1,2 \quad 1,3 \\
& 1,4 \quad 1,5 \quad 5, n \quad 6, n \\
& \begin{array}{rr}
0 & 0.098 \\
0 & 0.001 \\
0.018 & 0 \\
0.9 & 0 \\
0 & 0.98 \\
0 & 0.01 \\
0 & 0 \\
0 & 0 \\
0 & 0 \\
0 & 0
\end{array} \\
& \left.\begin{array}{rrrrr}
0.002 & 0 & 0 & 0 & 0 \\
0.096 & 0.003 & 0 & 0 & 0 \\
0.001 & 0.097 & 0.002 & 0 & 0 \\
0 & 0 & 0.1 & 0 & 0 \\
0.02 & 0 & 0 & 0 & 0 \\
0.96 & 0.03 & 0 & 0 & 0 \\
0.01 & 0.97 & 0.0066 & 0.0134 & 0 \\
0 & 0 & 0.33 & 0.67 & 0 \\
0 & 0.02 & 0 & 0.68 & 0.3 \\
0 & 0 & 0 & 0 & 1
\end{array}\right]
\end{aligned}
$$

The expected value and variance of the number of days that the MTS process will spend in each state are given by $\mathrm{N}=(\mathrm{I}-\mathrm{Q})^{-1}$ and $\mathrm{N}_{2}=\mathrm{N}\left(2 \mathrm{~N}_{\text {diagoeal }}-\mathrm{I}\right)-\mathrm{N}_{\mathrm{sq}}$ respectively.

$$
\begin{aligned}
& \text { Sus }
\end{aligned}
$$

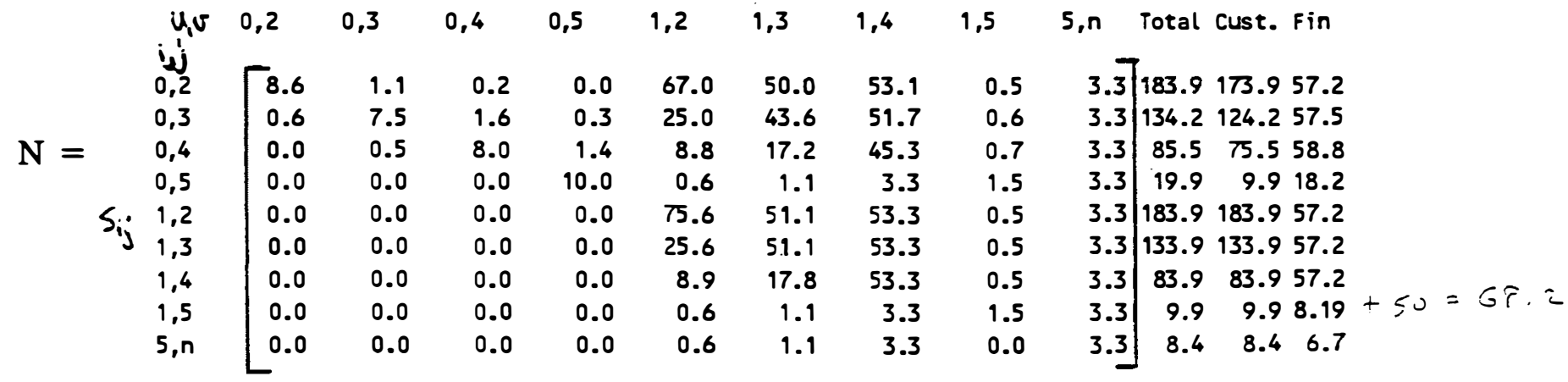

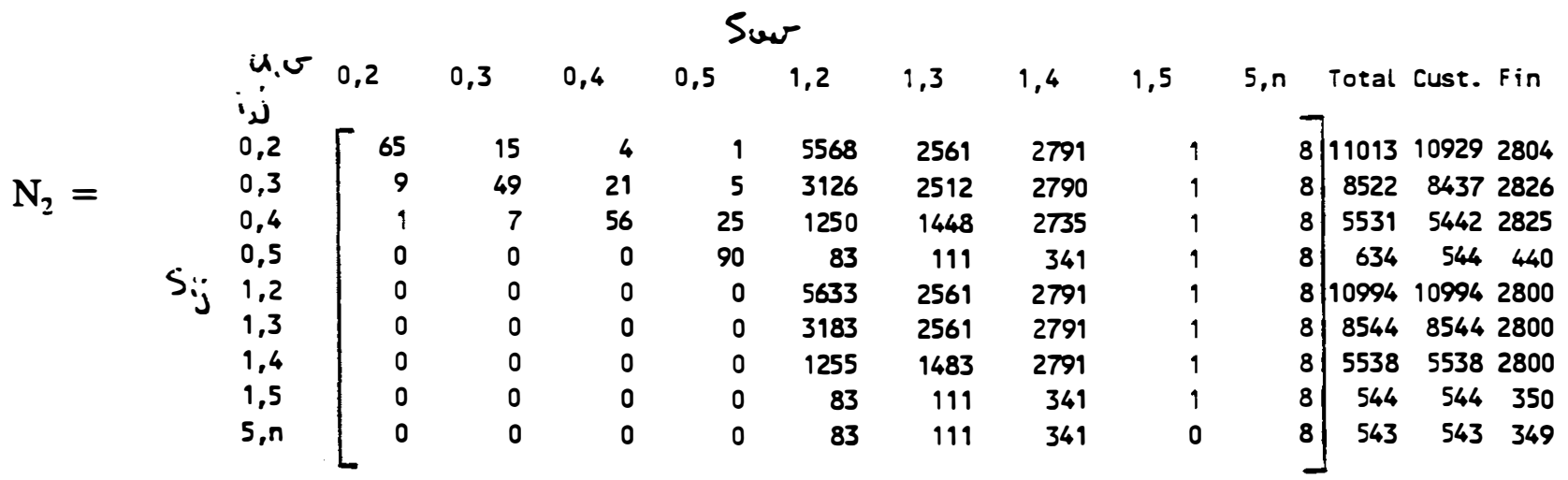


As in the case of the ATO, the different cycle time measurements depend on the initial state. The measurements of interest are those relating to different possible states at the time of arrival of an order, states $s_{1,2}$ through $s_{1,5}$ and the state representing beginning a parts order prior to the arrival of a customer order, state $\mathrm{s}_{0,2}$. (For ease of computation we assume that the number of days in a state are independent. See also Appendix 1.)

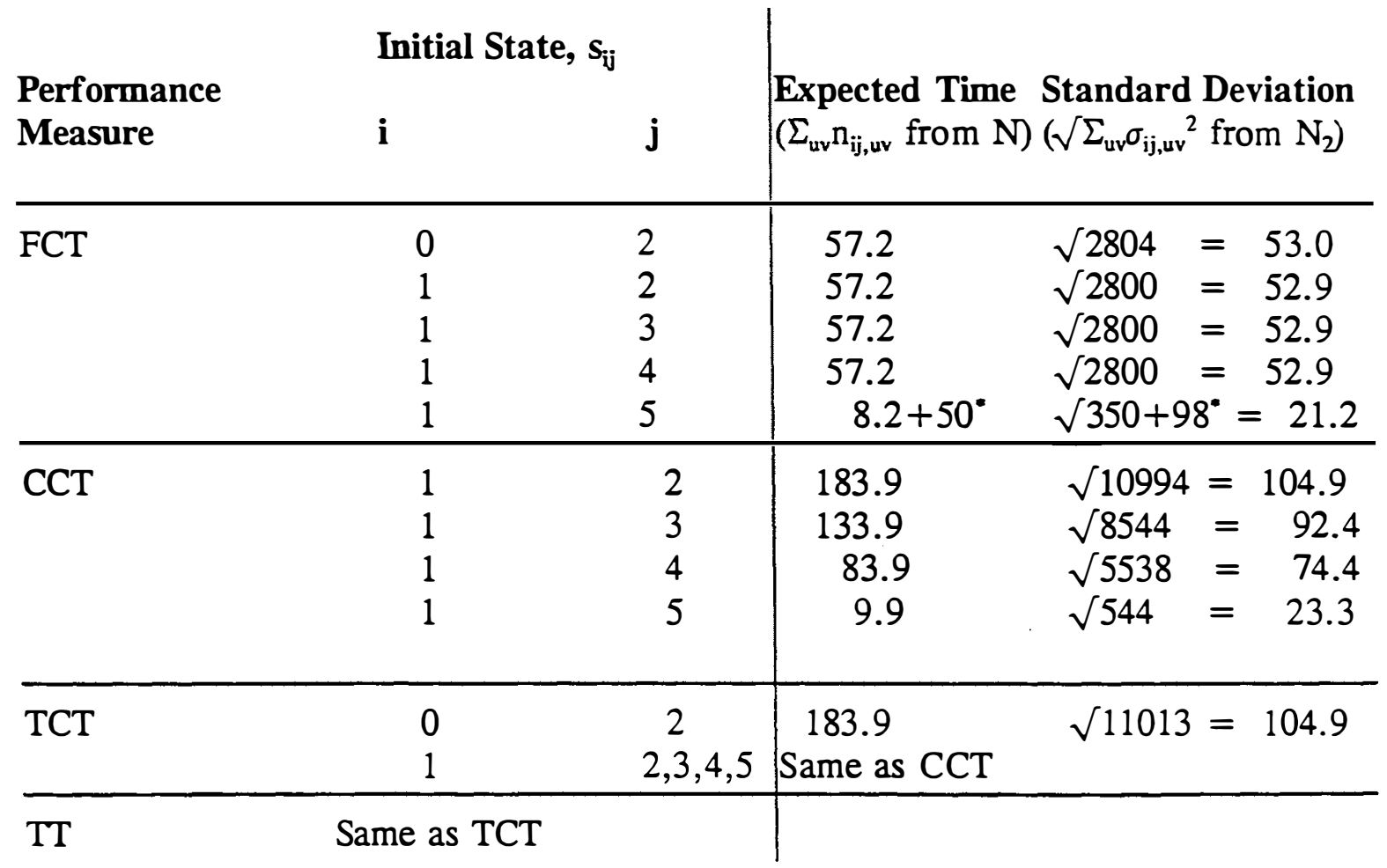

Notice that the total expected time from the Markov chain model is approximately the same as the total cycle time for the simple stochastic model in section 3. (See Figure 13.)

The total time, TT, has an expected value of 183.9 days with a standard deviation of 104.9 days. An upper bound on the total time is provided by equation 10. For example, if $k=3$ then

$$
\begin{aligned}
& \mathrm{P}(\mathrm{TCT} \geq 183.9+3 \times 104.9) \leq 1 / 3^{2} \\
\Rightarrow \quad & \mathrm{P}(\mathrm{TCT} \geq 498.6 \text { days }) \leq .11 .
\end{aligned}
$$


Sequence S1: Customer Order

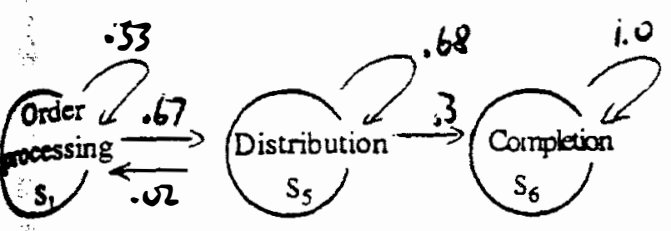

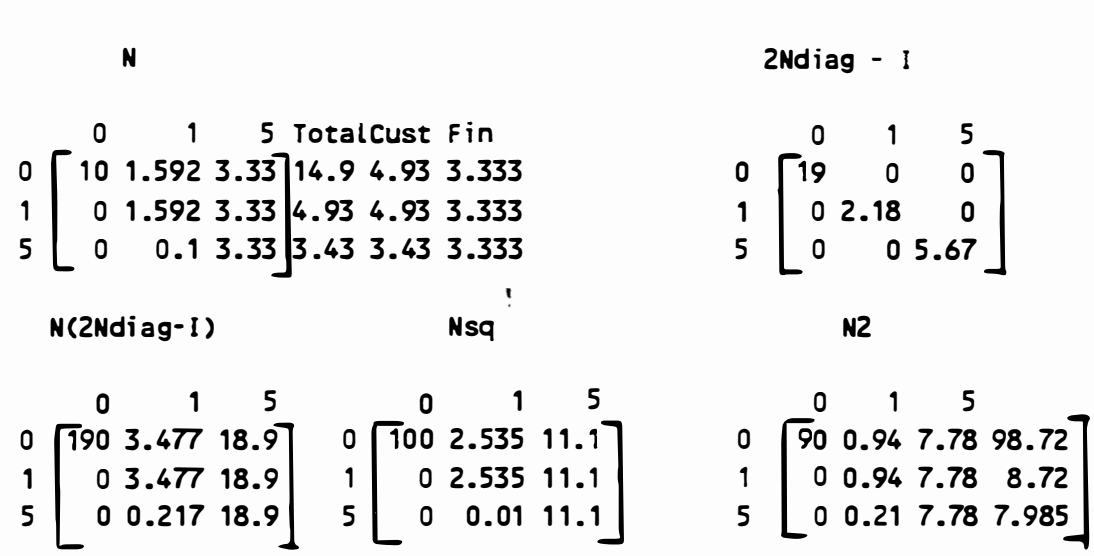

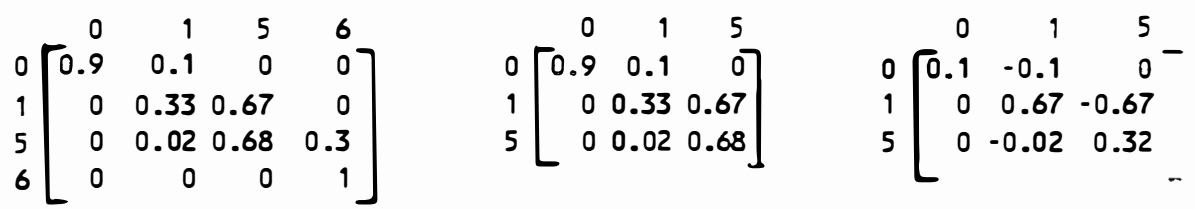

Sequence S2: Standard Product

Matrix P

$$
\begin{array}{r}
2 \\
3
\end{array}\left[\begin{array}{rrrr}
2 & 3 & 4 & 5 \\
0.08 & 0.02 & 0 & 0 \\
0 & 0.96 & 0.03 & 0 \\
0 & 0 & 0 & 1
\end{array}\right]
$$
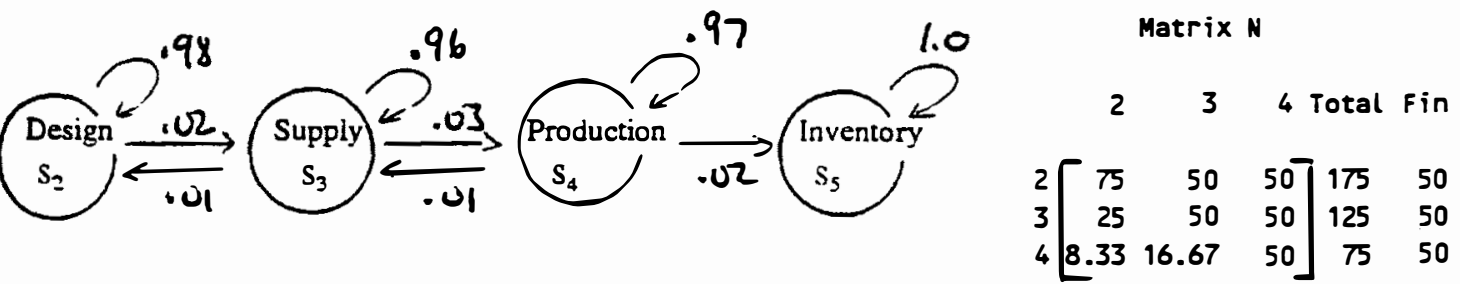

N(2Ndiag- 1$)$

234

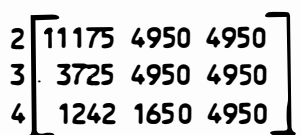

0

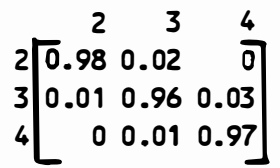

$4\left[\begin{array}{rrr}0.01 & 0.96 & 0.03 \\ 0 & 0.01 & 0.97\end{array}\right]$
(2Ndiag-I)

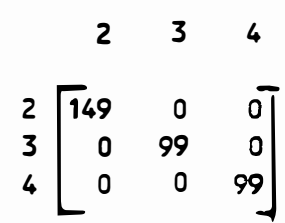

N2

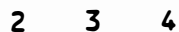

$2 \longdiv { 5 5 5 0 } 2 4 5 0 2 4 5 0$

3310024502450

$4 \quad 1172 \quad 1372 \quad 2450$

Figure 19 S1 Sequence and S2 Sequence Markov Chain Models for Example 2c 
As with the ATO case, identification of the sub-cycles (the states in the Markov model) that contribute most to a particular cycle time measure can be accomplished from this analysis, and also from an individual evaluation of $\mathrm{S} 1$ and $\mathrm{S} 2$-- Figure 19. For example, when $\mathrm{k}=3$ state $s_{2}$, design of standard products, followed by states $s_{3}$ and $s_{4}$, represent the largest elements of the total time in sequence S2. The activities in these sub-cycles should be targetted for cycle time reduction. 


\section{Queueing Models}

Three queueing models will be considered for cycle time management/reduction -- the simple queueing system, the k-stages series queueing system, and the open queueing system. For each of these models we define the following notation.

$\lambda=$ arrival rate $=$ average number of orders arriving or entering the system per unit time.

$\mu=$ service rate $=$ average number of orders completed or serviced per unit time.

$1 / \lambda=$ average time between arrivals of consecutive orders

$1 / \mu=$ average completion time for an order

$\rho \quad=\quad \lambda / \mu=$ utilization

$\mathrm{L}=$ average number of orders present in the system

$\mathrm{W}=$ average cycle time $=$ average time an order spends in the system

All averages are steady-state averages. These exist for each queueing model provided $\mu>\lambda . \mathrm{W}$ is the variable of most interest in cycle time management/reduction.

\subsection{The Simple Queueing System}

The simple queueing system consists of the elements shown in Figure 20. This system can be used to model an activity, a sub-cycle, or the complete manufacturing cycle. Expressions for computing $\mathrm{W}$ in the simple queueing system are given in Figure 21.

\subsection{The k-Stage Series Queueing System}

In this system an order is not complete until it has been served by a number of servers. (See Figure 22). Upon entering the system an order waits in queue at stage 1 until it is served. After completing stage 1 service, the order waits in queue at stage 2 and undergoes stage 2 service. This process continues until the order completes stage $\mathrm{k}$ service. This system is called a k-stage series queueing system.

The following theorem (due to Jackson [1957]; see Winston [p. 1084, 1991]) outlines how some of the results in Figure 21 may be used for this queueing system. 


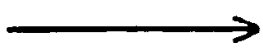

$\nabla$

Arrival, $\lambda$

Queue

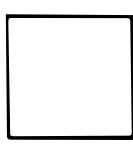

Service, $\mu$

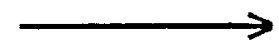

Output

Figure 20 Elements Comprising the Simple Queueing System 


\begin{tabular}{|c|c|}
\hline Queueing System $^{(1)}$ & $\begin{array}{l}\text { Expressions for } W \\
\text { the average time an order spends in the system } \\
\text { the }\end{array}$ \\
\hline 1. $\mathrm{D} / \mathrm{D} / 1 / \mathrm{GD} / \infty / \infty$ & $\mathbf{W}=\mathbf{0}$ \\
\hline 2. $\mathrm{M} / \mathrm{D} / 1 / \mathrm{GD} / \infty / \infty$ & $W=\frac{\lambda}{\ln (\mu-2)}+\frac{1}{\mu}$ \\
\hline 3. $\mathrm{M} / \mathrm{M} / 1 / \mathrm{GD} / \infty / \infty$ & $W=\frac{1}{\mu-\lambda}$ \\
\hline 4. $\mathrm{M} / \mathrm{M} / 1 / \mathrm{GD} / \mathrm{c} / \infty$ & $\begin{aligned} W=\frac{L}{\lambda\left(1-\pi_{c}\right)} \quad L & =\frac{\rho\left[1-(c+1) \rho^{c}+c \rho^{c+1}\right]}{\left(1-\rho^{c+1}\right)(1-\rho)} \\
\pi_{c} & =\rho^{c} \frac{1-p}{1-\rho^{c+1}}, \rho=\frac{\lambda}{\mu}\end{aligned}$ \\
\hline 5. $\mathrm{M} / \mathrm{M} / \mathrm{s} / \mathrm{GD} / \infty / \infty$ & $\begin{array}{l}W=\frac{L}{\lambda} \quad L=L_{q}+\frac{\lambda}{\mu}, L_{q}=\frac{P(j \geq s) \rho}{1-\rho} \\
P(j \geq s)=\frac{(s \rho)^{3} \pi_{0}}{s !(1-\rho)}, \rho=\frac{\lambda}{s \mu} \\
\pi_{0}=\left[\sum_{i=0}^{s-1} \frac{(s p)^{i}}{i !}+\frac{(s p)^{s}}{s !(1-\rho)}\right]^{-1}\end{array}$ \\
\hline 6. $M / G / 1 / G D / \infty / \infty$ & $\begin{array}{c}\mathrm{W}=\frac{1}{\mu}\left[1+\frac{\rho}{1-\rho}\left(\frac{1+\sigma_{s}^{2} / \operatorname{mean}_{s}^{2}}{2}\right)\right] \\
\begin{array}{l}\sigma_{\mathrm{s}}^{2}=\text { variance of service time distribution } \\
\text { mean }_{s}=\text { mean of the service time distribution }\end{array}\end{array}$ \\
\hline 7. $\mathrm{G} / \mathrm{G} / 1 / \mathrm{GD} / \infty / \infty$ & $\begin{array}{l}\mathrm{W}^{(3)}=\frac{1}{\mu}\left[1+\frac{\rho}{1-\rho}\left(\frac{\sigma^{2} \sqrt{ } \operatorname{mean}_{A}^{2}+\sigma_{S}^{2} / \text { mean }_{S}^{2}}{2}\right)\right] \\
\sigma_{A}^{2}=\text { variance of arrival time distribution } \\
\text { mean }_{A}=\text { mean of the arrival time distribution } \\
\sigma_{S}^{2}=\text { variance of service time distribution } \\
\text { mean }_{S}=\text { mean of the service time distribution }\end{array}$ \\
\hline 8. $\mathrm{M} / \mathrm{M} / \mathrm{R} / \mathrm{GD} / \mathrm{K} / \mathrm{K}$ & $\begin{array}{rl}W=\frac{L}{\bar{\lambda}} \quad \bar{\lambda}=\lambda(K-L), L=\sum_{j=0}^{K} j \pi_{j} \\
\pi_{j}=\frac{\left(\begin{array}{c}K \\
j\end{array}\right) \rho^{j} \pi_{0} \quad j=0,1, \ldots, R}{\left(\begin{array}{c}K \\
j\end{array}\right) \rho^{j} j ! \pi_{0}} \\
R ! R^{j-R} & j=R+1, R+2, \ldots, K\end{array}$ \\
\hline
\end{tabular}

Notes 1. Each queueing system is described by six characteristics 1/2/3/4/5/6 where:

1 The nature of the arrival process (M -exponential, D - deterministic, $E_{x}$ - Erlang, $G$ general).

2 The nature of the service time

3 The number of servers

4 The queue discipline (FCFS, LCFS, SIRO - service in random order, GD - general discipline).

5 The maximum number of orders in the system (that is, orders waiting and orders in service).

6 The size of population from which the orders are drawn.

2. These expressions hold when the queue is in steady state. Steady state exists when $\mu>\lambda$. See, for example, Winston [chapter 22. 1991].

3. See Kingman [?]. 


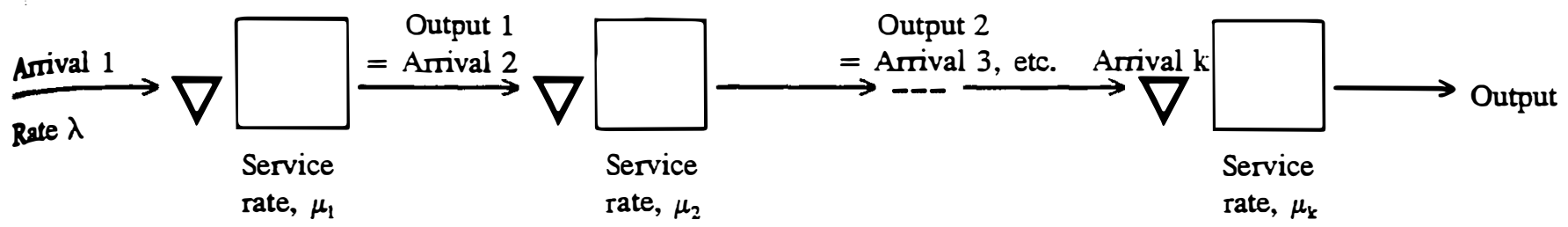

Eigure 22 Elements Comprising the k-Stage Series Queueing Svstem

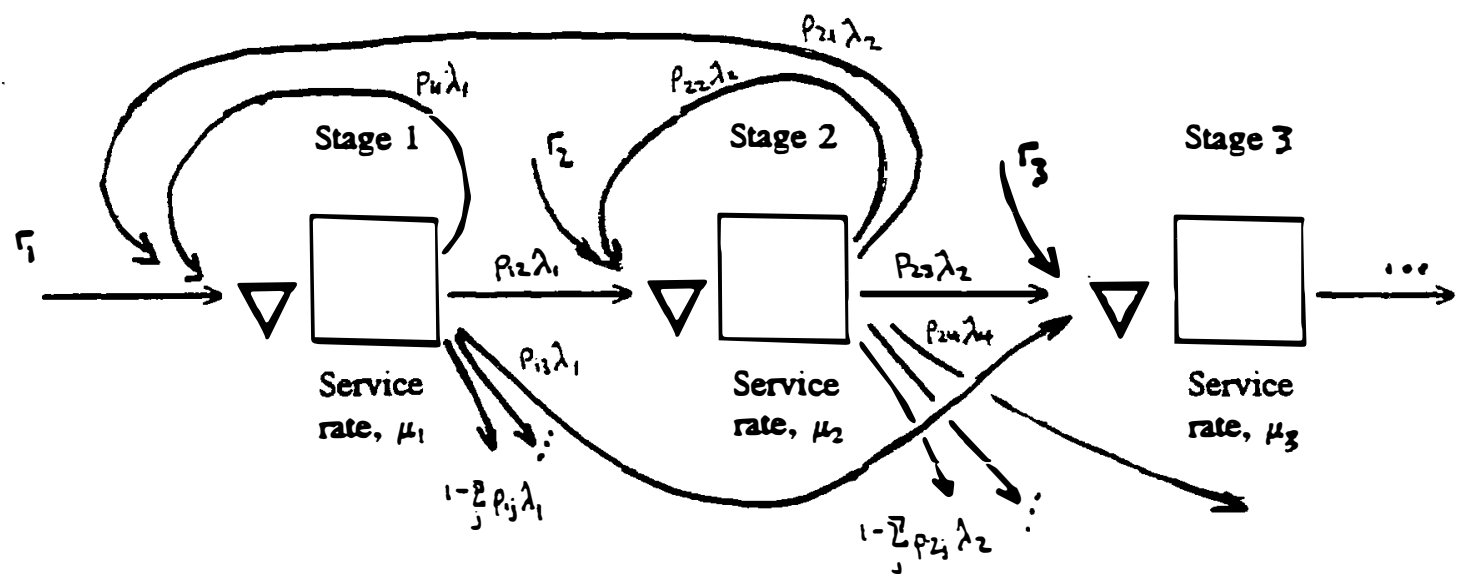

Figure 23 Elements Comprising the Open Queueing System 
The interarrival times for arrivals to each stage of the queueing system are

exponential with rate $\lambda$ if the following conditions hold.

1. Interarrival times at stage 1 are exponential with rate $\lambda$.

2. Service times for each server at each stage are exponential.

3. Each stage has an infinite-capacity queue.

4. $\mu>\lambda$ at each stage.

This theorem implies that each stage may be analyzed as a simple $M / M$ queueing system. Consequently results 3 and 5 from Figure 21 may be used.

\subsection{The Open Queueing System}

The k-stage series queueing system may be generalized to:

1. Permit orders from outside the queueing system to enter the system at each stage,

2. Permit orders inside the system to leave after completion of service at stages prior to the last stage,

3. Permit orders to re-enter previous stages for additional service, and

4. Permit orders to skip stages.

The resulting system is called an open queueing system. The elements that comprise it are shown in Figure 23 . Each stage $j=1,2, \ldots, k$ in an open queueing system can be treated a simple $\mathrm{M} / \mathrm{M} / \mathrm{s}_{\mathrm{j}} / \mathrm{GD} / \infty / \infty$ queue with arrival rate $\lambda_{\mathrm{j}}$ and service rate $\mu_{\mathrm{j}}$, when the following assumptions hold.

1. Orders from outside the queueing system arrive at stage $j$ at rate $r_{j}$. These interarrival times are exponentially distributed.

2. After completion of service at stage $i$, an order joins the queue at stage $j$ with probability $\mathrm{P}_{\mathrm{ij}}$. The order leaves the system with probability $1-\Sigma_{j=1}^{k} \mathrm{P}_{\mathrm{ij}}$.

3. Each stage $j=1,2, \ldots, k$ consists of $s_{j}$ exponential servers each operating at rate $s_{j} \mu_{j}>\lambda_{j}$.

$\lambda_{j}=r_{j}+\sum_{i=1}^{k} p_{i j} \lambda_{j}$ is the rate at which orders arrive at stage $j$. Then $L$, the expected number of orders in the queueing system, and $\mathrm{W}$, the average time an order spends in the system, are computed from $L=\sum_{i=0}^{s-1} L_{i}, \quad W=L / \lambda, \quad \lambda=\sum_{j=1}^{k} r_{j}$ where $L_{j}$ is the expected number of orders 
at stage $\mathrm{j}$.

The three queueing models are used as follows in cycle time management/reduction.

1. The simple queueing system may be used to model an activity, a sub-cycle, or the complete manufacturing cycle in the MTO, ATO and MTS environments. When used for other than an activity the model is an aggregate model.

2. When the expressions for cycle time, $W$, in Figure 21 are used it is possible to analyze the effect on cycle time of changes in arrival and service time distributions, limits on queue size, the number of servers, and so on.

3. Cycle time in the MTO environment can be modelled as a $k$-stage series queueing system.

4. Cycle time in the ATO and MTS environments can be modelled as an open queueing system.

In what follows simple examples are worked to illustrate these models. Observations and insights follow.

Example 3 - The Simple Queueing Model

Consider the distribution sub-cycle in a small company. The distribution department receives orders from the production department which it packages and ships to customers. An average of 10 orders are received each day. It takes an average of 40 minutes (.08 days) to complete the distribution activities for each order. The distribution department can be modelled as a simple queue.

$\underline{1 . D / D / 1}$

2. $\mathrm{M} / \mathrm{D} / 1$

As $\lambda=10$ and $\mu=1 / .08=12.5$, result 2 From Figure 21 gives $W=.24$. That is, the average cycle time time is .4 days, when an average of 10 orders per day are shipped.

\section{3. $\mathrm{M} / \mathrm{M} / 1 / \mathrm{GD} / \infty / \infty$}

The distribution sub-cycle can be modelled as a simple $M / M / 1 / G D / \infty / \infty$ with $\lambda=10$ and $\mu=1 / .08=12.5$. Result 3 From Figure 21 gives $W=.4$. That is, the average cycle time time is .4 days. (An average of 10 orders per day are shipped.) 


\section{4. $\mathrm{M} / \mathrm{M} / 1 / \mathrm{GD} / \mathrm{c} / \infty$}

Suppose there is a physical limitation on the number of orders that can be accomodated by the distribution department. No more than $c=6$ orders can be handled at any one time. Result 4 from Figure 21 applies in this case. This gives an average cycle time is $\mathrm{W}=.23$ days. However on average only 9.3 orders are shipped each day. (An arriving order will find the system full with probability $\pi_{6}=.0663$ and so at steady state $\lambda$ (1$\left.\pi_{6}\right)=9.3$ orders per day will move through the system.) The capacity constraint has reduced the cycle time but has also reduced the output.

\section{5. $\mathrm{M} / \mathrm{M} / \mathrm{s} / \mathrm{GD} / \infty / \infty$}

Suppose that the distribution department consists of two small workcenters, each of which takes 77 minutes (.16 days) to process an order. Then $\lambda=10, \mu=1 / .16=6.25$ and $\mathrm{s}=2$. Result 5 from Figure 21 gives an average cycle time of $\mathrm{W}=.44$ days. (In this case an average of 10 orders are shipped each day.)

\section{6. $\mathrm{M} / \mathrm{G} / 1 / \mathrm{GD} / \infty / \infty$}

Suppose that the service time distribution is unknown. However estimates of the mean and standard deviation are available. Result 6 from Figure 21 applies in this case.

\begin{tabular}{cc|c}
$\begin{array}{c}\text { Service } \\
\text { Mean, } \\
1 / \mu\end{array}$ & $\begin{array}{c}\text { Time } \\
\text { Standard } \\
\text { deviation, } \sigma_{S}\end{array}$ & $\begin{array}{c}\text { Expected Cycle Time, } \\
\mathbf{W}\end{array}$ \\
\hline $1 / 12.5=.08$ days & $0^{(1)}$ & .24 days \\
.08 & .04 days & .28 \\
.08 & $\sqrt{ }\left(1 / 12.5^{2}\right)=.08^{(2)}$ & .4 \\
.08 & .12 & .6 \\
.08 & .16 & .88
\end{tabular}

1. $\mathrm{M} / \mathrm{D} / 1 / \infty / \infty$ result

2. $\mathrm{M} / \mathrm{M} / 1 / \infty / \infty$ result 
Notice how increases in the variability of the service time increase the expected cycle time.

\section{7. $\mathrm{G} / \mathrm{G} / 1 / \mathrm{GD} / \infty / \infty$}

Suppose that the distributions of the interarrival time and the service time are both unknown. If estimates of the means and standard deviations of these random variables are available, then result 7 from Figure 21 can be used. Some results are plotted in Figure 24 where $\mathrm{CV}_{\mathrm{A}}=\sigma_{\mathrm{A}}^{2} / \mathrm{mean}_{\mathrm{A}}{ }_{\mathrm{A}}$ and $\mathrm{CV}_{\mathrm{s}}=\sigma_{\mathrm{S}}^{2} / \mathrm{mean}^{2} \mathrm{~s}$ are the coefficients of variation of the arrival and service time distributions. In Figure 24 we set $\lambda=10$ and $\mu=12.5$, so that $\operatorname{mean}_{\mathrm{A}}=1 / \lambda=.1$ days and $\operatorname{mean}_{\mathrm{S}}=1 / \mu=.08$ days. Note that point 1 is the $D / D / 1 / \infty / \infty$ result and point 2 is the $M / M / 1 / \infty / \infty$ result. Notice that the variability of the arrival time and the variability of the service time have equal effects on the cycle time. That is $\delta \mathrm{W} / \delta \sigma_{\mathrm{A}}^{2}=\delta \mathrm{W} / \delta \sigma_{\mathrm{s}}^{2}$.

\section{8. $\mathrm{M} / \mathrm{M} / \mathrm{R} / \mathrm{GD} / \mathrm{K} / \mathrm{K}$}

Suppose that the company is operating in an MTO environment. No more than 30 orders are in the company at any one time. New orders arrive at an average rate of 10 per day. The distribution department has two workcenters each of which can process an order in .16 days. In this case a simple $\mathrm{M} / \mathrm{M} / \mathrm{R} / \mathrm{GD} / \mathrm{K} / \mathrm{K}$ queue with $\lambda=10, \mu=6.25, \mathrm{R}=2$ and $\mathrm{K}=30$ may be used. Result 8 from Figure 21 gives an average cycle time of $\mathrm{W}=2.3$ days.

\section{Observations}

The goal in cycle time management/reduction is to reduce the cycle time, W. Our analysis of the simple queueing system suggests that this can be accomplished in four ways.

i) Increase the service rate $\mu$. This reduces cycle time because 1.once an order begins service it is completed more quickly, and 2.the time spent waiting in the queue is less 
because the orders ahead in the queue will be serviced more quickly. Ways to increase $\mu$ include multi-skilling operators, reducing setup times, reducing breakdowns, investing in additional equipment, and so on. Note that some of these options, such as investing in additional equipment, are costly and hence are less attractive than others.

ii) Decrease the variability of the service time, $\sigma_{s}^{2}$. Part 6 of Example 3 illustrated the effect of this variability on the cycle time. Ways to reduce $\sigma_{\mathrm{s}}^{2}$ include using better trained operators, sharpening operating procedures, improving equipment to reduce scrap, using more automation, and so on.

iii) Decrease the variability of the arrival time, $\sigma_{A}^{2}$. Part 7 of Example 3 illustrated the effect of this variability on the cycle. When the arrival process and service process both have general distributions the variability of the arrival time and the variability of the service time have equal effects on the cycle time. (That is $\delta \mathrm{W} / \delta \sigma_{\mathrm{A}}^{2}=\delta \mathrm{W} / \delta \sigma_{\mathrm{s}}^{2}$.) One way to reduce $\sigma_{\mathrm{A}}^{2}$ is to use a scheduling system to schedule arrivals.

iv) Place a limit, c, on the number of orders allowed in the system. Part 4 of Example 3 showed that this reduces the cycle time because it tums away orders when the queue becomes long. The cycle time of the orders that are accepted is shorter, but because some orders are turned away the output is lower (by a factor of $1-\pi_{\mathrm{c}}$ ). This would make the use of a limit unattractive for many cycle time management/reduction problems.

v) Replace multiple "small" servers with a single "large" server. All things being equal, $\mathrm{W}$ for an $\mathrm{M} / \mathrm{M} / 1 / \mathrm{GD} / \infty / \infty$ queue (result 4 in Figure 21) will be smaller than $\mathrm{W}$ for an "equivalent" M/M/s/GD/ $\infty / \infty$ queue (result 5 in Figure 21).

Example 4a -- The k-Stage Series Queueing System in the MTO Environment

Suppose the 5-stage series queueing system shown in Figure 25 models the manufacturing cycle time for a company operating in an MTO environment. Suppose also Jackson's theorem (section 5.2) holds for this problem. Then the cycle times are:

\begin{tabular}{|c|c|c|}
\hline Queue, $\mathbf{Q}_{\mathrm{i}}$ & Type of Queue & Cycle Time, $W_{i}$ \\
\hline cessing & $\mathrm{D} / \infty / \infty$ & .4 days \\
\hline $\mathrm{Q}_{2}$ : Design & $\mathrm{M} / \mathrm{M} / 1 / \mathrm{GD} / \infty / \infty$ & 2 \\
\hline $\mathrm{Q}_{3}$ : Supply management & $\mathrm{M} / \mathrm{M} / 2 / \mathrm{GD} / \infty / \infty$ & .55 \\
\hline $\mathrm{Q}_{4}:$ Production & $\mathrm{M} / \mathrm{M} / 4 / \mathrm{GD} / \infty / \infty$ & .4 \\
\hline $\mathrm{Q}_{s}$ : Distribution & $\mathrm{M} / \mathrm{M} / 1 / \mathrm{GD} / \infty / \infty$ & $\frac{.5}{3.85}$ davs \\
\hline
\end{tabular}

An average of 3.85 days is required to complete an order. The design sub-cycle is largest component of cycle time. It would be targeted for cycle time reduction. Suppose that 


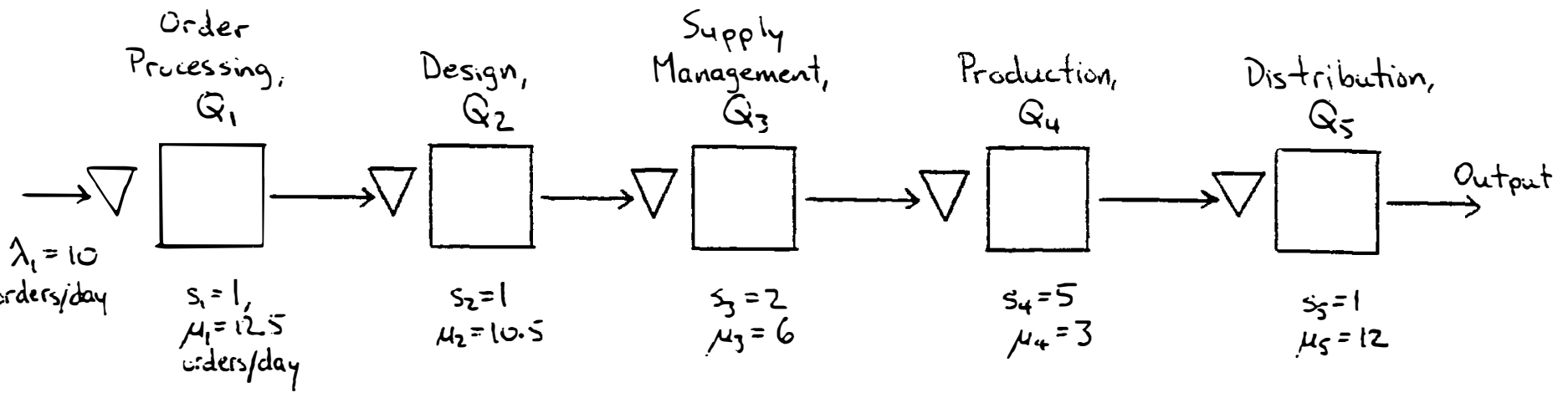

Figure 25 5-Stage Series Queuing Svstem Model for MTO Environment in Example 4a 
the variability of the service time in the design department was reduced by 50 percent. Then $\mathrm{Q}_{2}$ would be a $\mathrm{M} / \mathrm{G} / 1 / \mathrm{GD} / \infty / \infty$ queue with $\lambda=10, \mu=10.5, \operatorname{mean}_{\mathrm{s}}=1 / \mu=.095$ and $\sigma_{\mathrm{S}}^{2}=.5\left(1 / \mu^{2}\right)=.0045$, which gives $\mathrm{W}_{2}=1.5$ days -- a cycle time reduction of .5 days. Now suppose that some improvements to the CAD system decreased the average time required to complete a design from .095 days to .085 days. Then $\mathrm{Q}_{2}$ has $\lambda=10, \mu=1 / .085=11.76$, mean $_{\mathrm{s}}=.085$ and $\sigma_{\mathrm{s}}^{2}=.0045$, which gives $\mathrm{W}_{2}=.5$ days -- an additional cycle time reduction of one day.

\section{Example 4b - Open Queueing System for the ATO and MTS Environments}

Suppose that the open queueing system shown in Figure 26 is a model for manufacturing cycle time in a company operating in an ATO environment. Each week an average of two new customer orders are received ( $r_{1}=2$ orders per week) in the order processing department (queue, $\mathrm{Q}_{1}$ ). Customer orders move through order processing, design, suppliers, production and distribution (queues $\mathrm{Q}_{1}, \mathrm{Q}_{2}, \ldots, \mathrm{Q}_{5}$ ) before they are completed (queue $\mathrm{Q}_{6}$ ). Simple orders are serviced more quickly than complex ones (which may cycle through a department a few times). Standard components move through the design department, suppliers, production and inventory (queues $\mathrm{Q}_{7}, \mathrm{Q}_{8}, \mathrm{Q}_{9}, \mathrm{Q}_{10}$ ) before being assembled into unique products for customer orders (queue $\mathrm{Q}_{4}$ ). An average of two manufacturing orders for standard components are started each week ( $r_{7}=2$ orders per week).

The service rates for customer orders and manufacturing orders, $\mu_{1}, \mu_{2}, \ldots, \mu_{10}$ are shown in Figure 27. The arrival rates $\lambda_{1}, \lambda_{2}, \ldots, \lambda_{10}$ are calculated as shown in Figure 26. We assume that arrival times and service times are exponentially distributed. Since $\mu_{\mathrm{i}}>\lambda_{\mathrm{i}}$ at each queue, $Q_{\mathfrak{i}}$, steady state exists and each queue can be modelled as a simple $M / M$ queue. Result 4 from Figure 21 is used to calculate the expected cycle times, $\mathrm{W}_{\mathrm{i}}$. 


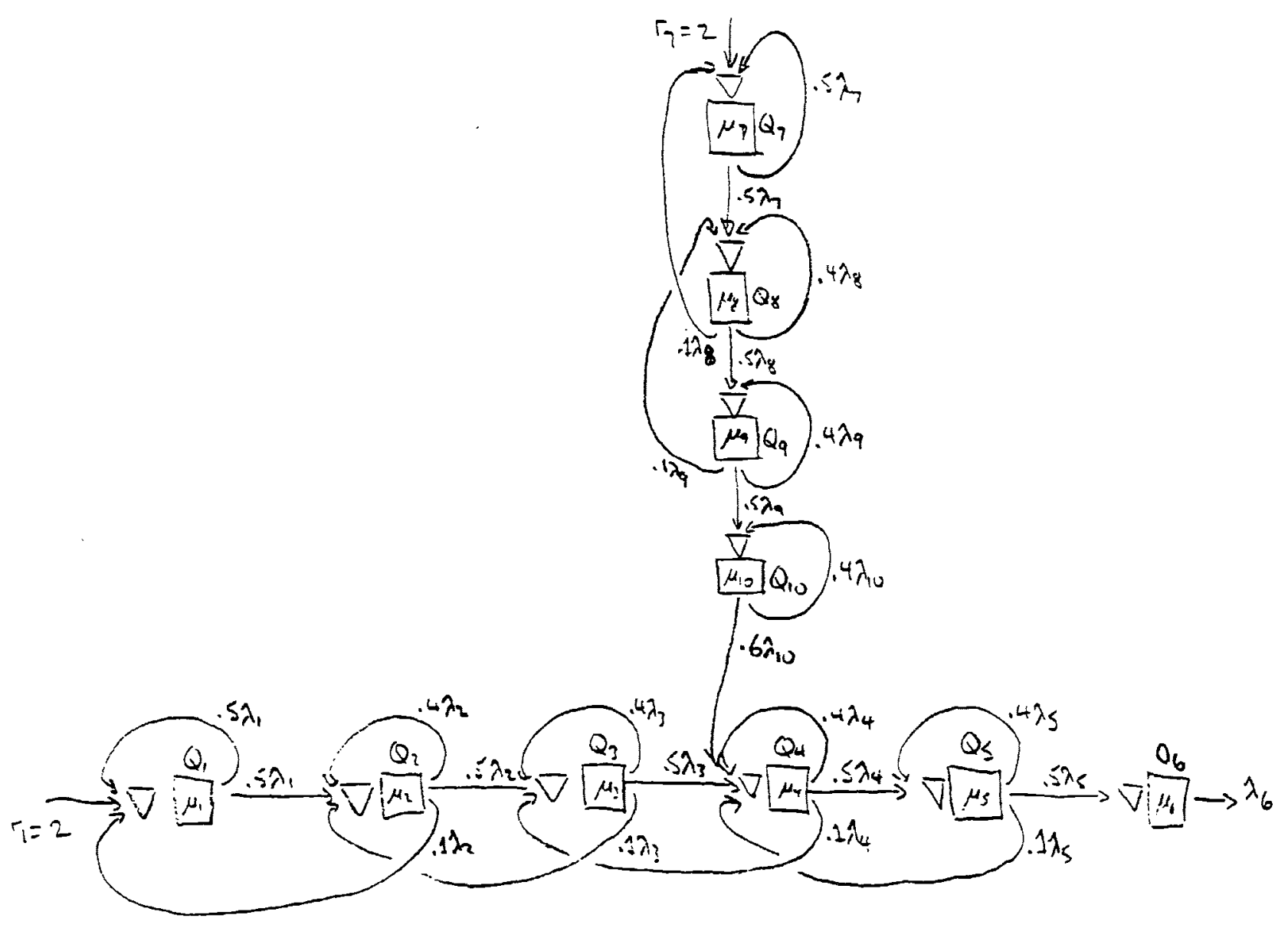

Figure 26 Open Queuing System Model for ATO Environment in Example 4b 


\begin{tabular}{|c|c|c|c|c|}
\hline Queue, $\mathbf{Q}_{\mathbf{i}}$ & $\begin{array}{c}\text { Arrival Rate, } \\
\text { Orders pe }\end{array}$ & Week & $\begin{array}{c}\text { Service Rate, } \\
\mu_{i} \\
\text { Orders per Week }\end{array}$ & $\begin{array}{c}\text { Expected Cycle Time, } \\
W_{i} \\
\text { Weeks }\end{array}$ \\
\hline $\mathrm{Q}_{1}$ : Order processing & $\lambda_{1}=\overrightarrow{r_{1}}+.5 \lambda_{1}+.1 \lambda_{2}$ & $=5$ & 6 & 1.0 \\
\hline $\mathrm{Q}_{2}$ : Design - final assembly & $\lambda_{2}=.5 \lambda_{1}+.4 \lambda_{2}+.1 \lambda_{3}$ & $=5.2$ & 6 & 1.3 \\
\hline Q: Supply - final assembly & $\lambda_{3}=.5 \lambda_{2}+.4 \lambda_{3}+.1 \lambda_{4}$ & $=5.9$ & 7 & .9 \\
\hline $\mathrm{Q}_{4}$ : Production - final assembly & $\lambda_{4}=.5 \lambda_{3}+.4 \lambda_{1}+.1 \lambda_{5}+.6 \lambda_{10}$ & $=9.6$ & 10 & 2.5 \\
\hline Q: Distribution & $\lambda_{5}=.5 \lambda_{4}+.4 \lambda_{5}$ & $=8$ & 10 & .5 \\
\hline$Q_{6}:$ Completion & $\lambda_{6}=.5 \lambda_{5}$ & $=4$ & $\infty$ & 0 \\
\hline$Q_{7}$ : Design - standard components & $\lambda_{7}=\mathrm{r}_{7}+.5 \lambda_{7}+.1 \lambda_{8}$ & $=5$ & 6 & 1.0 \\
\hline $\mathrm{Q}_{8}:$ Supply - standard components & $\lambda_{8}=.5 \lambda_{7}+.4 \lambda_{8}+.1 \lambda_{9}$ & $=4.8$ & 6 & .8 \\
\hline Q: Production - standard components & $\lambda_{g}=.5 \lambda_{g}+.4 \lambda_{g}$ & $=4$ & 5 & 1.0 \\
\hline $\mathrm{Q}_{10}$ : Inventory - standard components & $\lambda_{10}=.5 \lambda_{9}+.4 \lambda_{10}$ & $=3.3$ & 4 & 1.4 \\
\hline
\end{tabular}

Notes 1. Each queue is a simple $\mathrm{M} / \mathrm{M} / \mathrm{1} / \mathrm{GD} / \infty / \infty$ queue.

2. All $\mu_{i}>\lambda_{i}$, so steady state exists for all queues.

Figure $2 \not \vec{\beta}$ Arrival Rates, Service Rates and Expected Cycle Times for Example 4b 
The expected cycle time for a customer order is,

$$
\mathrm{W}_{\text {crescomorder }}=\sum_{\mathrm{i}=1}^{6} \mathrm{~W}_{\mathrm{i}}=6.2 \text { weeks }
$$

and the expected number of customer orders in the company is,

$$
\mathrm{L}_{\text {Customer Order }}=\mathrm{r}_{1} \mathrm{~W}_{\text {Customer Order }}=2 \times 6.2=12.4 \text { orders. }
$$

The expected cycle time for a manufacturing order is,

$$
\mathrm{W}_{\text {Mmantimsorte }}=\sum_{\mathrm{i}=7}^{10} \mathrm{~W}_{\mathrm{i}}=4.2 \text { weeks. }
$$

The largest cycle time occurs in queue $\mathrm{Q}_{4}$, production of final assemblies, followed by $\mathrm{Q}_{10}$, inventory of standard components. These queues, or sub-cycles, would be targeted for cycle time managment/reduction efforts. (See the observations at the end of Example 3.) 


\section{Appendix \\ Other Results for the Simple Markov Chain Model}

It is easy to show that equation 9 can be simplifed to give,

$\sigma_{1 j}^{2}=n_{i j}\left(2 n_{i j}-1\right)-n_{1 j}^{2}$,

where $n_{i j}$ is computed from equation 8 . It is also true that $n_{1 j}=n_{i j}$ (although this is difficult to prove). The independent variable in equation 11 can now be written as

$$
\begin{aligned}
E\left(\text { TCT }^{\text {MTO }}\right)+k \sigma\left(\text { TCT }^{\text {MTO }}\right) & =\Sigma_{j} n_{1 j}+k \sqrt{ } \Sigma_{j} \sigma_{1 j}{ }^{2} \\
& =\Sigma_{j} n_{1 j}+k \sqrt{ } \Sigma_{j}\left(n_{i j}\left(2 n_{j j}-1\right)-n_{1 j}{ }^{2}\right) \\
& =f\left(n_{1 j}\right) .
\end{aligned}
$$

Consequently it is not necessary to calculate $\sigma_{1 j}{ }^{2}$ for the purpose of identifying subcycles or activities for cycle time reduction. Rather it is only necessary to order subcycles and activities in decreasing order of $n_{1 j}$. Those at the top of the list would be targeted for cycle time reduction.

\section{Dropping the Assumption of Independence of Times To Absorption}

Let $\mathrm{m}$ denote the time to absorption. That is, $\mathrm{m}$ is the number of periods, including the original position, in which the process is in one of the transient states $s_{1}, s_{2}, \ldots, s_{5}$. Kemeny and Snell [pp. 43-57, 1976] show that the mean and variance of $m$ can be computed from;

$$
\begin{aligned}
& \mathrm{E}_{\xi}(\mathrm{m})=\tau=\mathrm{N} \xi \\
& \operatorname{Var}_{\mathrm{i}}(\mathrm{m})=\tau_{2}=(2 \mathrm{~N}-\mathrm{I}) \tau-\tau_{\mathrm{sq}}
\end{aligned}
$$

where $\quad s_{\mathrm{i}}-$ is a transient state,

$\xi$ - is a column vector having all elements equal to 1 , and

$\tau_{\mathrm{sq}}$ - is formed from $\tau$ by squaring each element.

The distribution of $\mathrm{m}$ is not known. (It is interesting to note that when the process is a regular Markov chain rather than an absorbing Markov chain, similar expressions can be 
developed for the mean and variance of the number of periods each state is occupied during $n$ transitions, and this random variable has a normal distribution when $\mathrm{n}$ is large).

\section{Example 2a (continued)}

Recall Example la from section 3.1. P and $\mathrm{N}$ are reproduced below.

$$
\begin{array}{c|cccccc|l}
\mathbf{P}=\mathrm{s}_{1} & \mathrm{~s}_{1} & \mathrm{~s}_{2} & \mathrm{~s}_{3} & \mathrm{~s}_{4} & \mathrm{~s}_{5} & \mathrm{~s}_{6} & \\
\mathrm{~s}_{2} & .001 & .09 & 0 & 0 & 0 & 0 & \text { Order } \\
\mathrm{s}_{3} & 0 & .079 & .02 & 0 & 0 & 0 & \text { Design } \\
\mathrm{s}_{4} & 0 & 0 & .001 & .969 & .03 & 0 & \text { Production } \\
\mathrm{s}_{5} & 0 & 0 & 0 & .003 & .667 & .33 & \text { Distribution } \\
\mathrm{s}_{6} & 0 & 0 & 0 & 0 & 0 & 1 & \text { Completion }
\end{array}
$$

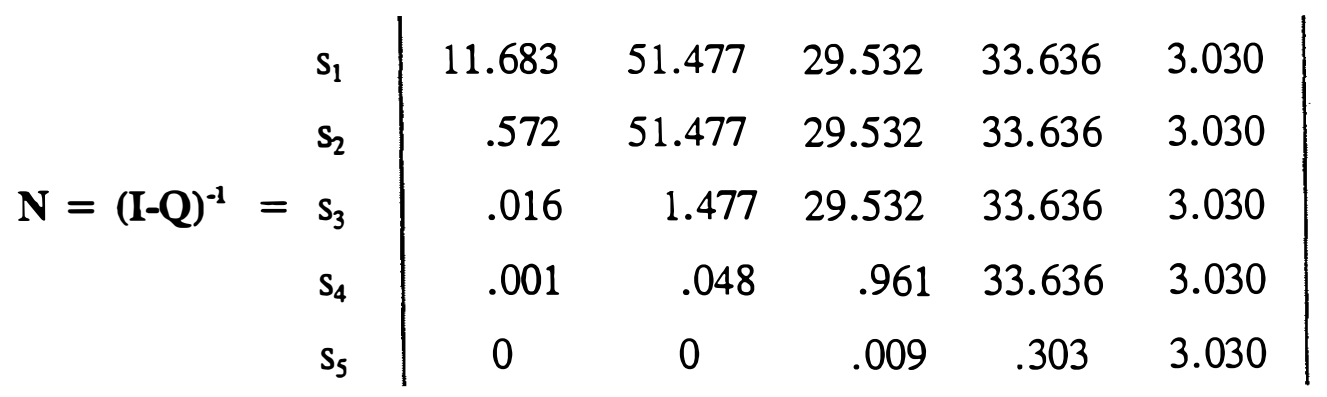

The time period is one day. That is, each element $\mathrm{p}_{\mathrm{ij}}$ of $\mathrm{P}$ is the probability that an order which is currently in state $s_{\mathrm{i}}$ will be in state $s_{\mathrm{j}}$ the next day. Then $\tau=\mathrm{N} \xi$ and $\tau_{2}=(2 \mathrm{~N}-\mathrm{I}) \tau-\tau_{\mathrm{sq}}$ are:

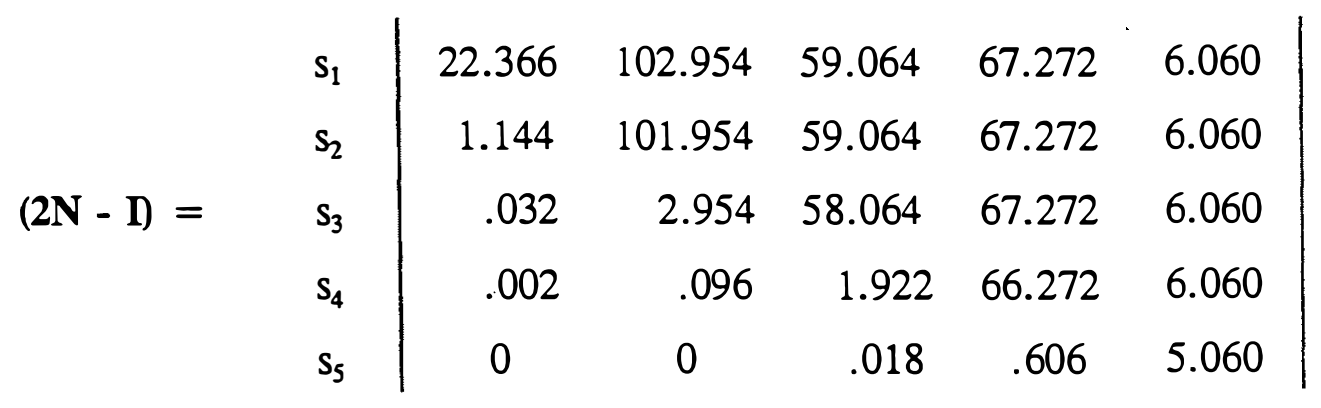




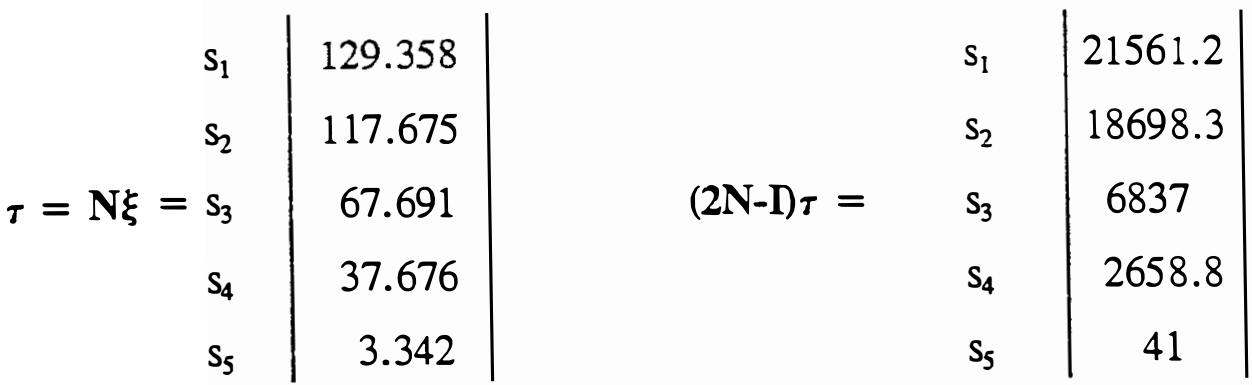

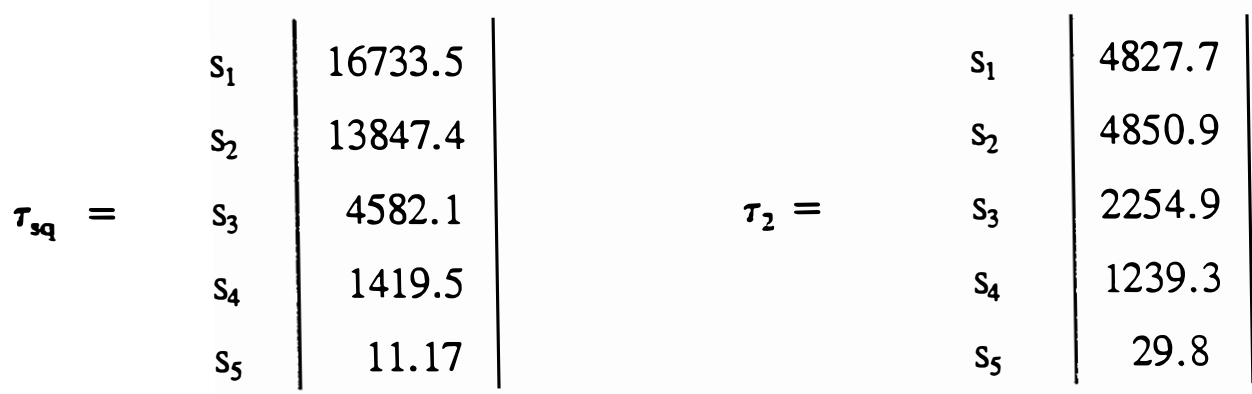

Since all orders start in state $s_{1}$, the mean and standard deviation of the number of days it will take to complete an order are $\mathrm{E}_{1}(\mathrm{~m})=129.4$ days and $\sqrt{\operatorname{Var}_{1}}(\mathrm{~m})=\sqrt{4827.7}=69.5$ days. Notice how close the standard deviation is to the estimate made in section 4.1 when the number of days in a state was assumed to be independent. 


\section{$\underline{\text { References }}$}

Chase, R.B. and N.J. Aquilano, Production and Operations Management, Sixth Edition, Richard D. Irwin, Inc., Homewood, Illinois, 1992.

Dertouzos, M., Lester, R., and R. Solow, Made In America: Regaining The Competitive Edge, Harper Perennial Press, New York, 1990.

Flapper, S.D., Miltenburg, G.J., and J. Wijngaard, "Imbedding JIT into MRP", International Journal of Production Research, 29, 2, 329-341, 1991.

Hall, R.W., Zero Inventories, Homewood, IL.: Dow Jones - Irwin Press, 1983.

Kemeny, J.G., and J.L. Snell, Finite Markov Chains, Springer-Verlag Publishing Co., New York, 1976.

Miltenburg, G.J. and J. Wijngaard, "Designing and phasing in just-in-time production systems", International Journal of Production Research, 29, 1, 115-131, 1991.

Monden, Y., Toyota Production System, Atlanta, GA: Industrial Engineering and Management Press, 1983.

Moody, P.E.(editor), Strategic Manufacturing, Dow-Jones Irwin, Howewood, Illinois, 1990.

Ohno, T., Toyota Production System: Beyond Large Scale Production, Cambridge, Massachusetts: Productivity Press, 1988.

Schonberger, R.J., Japanese Manufacturing Techniques, New York: Free Press, 1982.

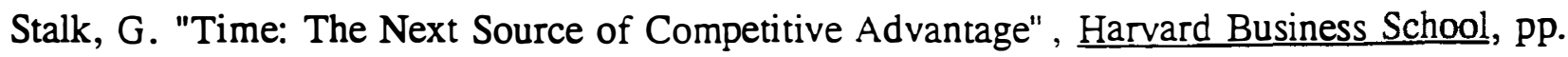
41-51, July-August 1988.

Winston, W.L., Operations Research: Applications and Algorithms, Second Edition, PWS-Kent Publishing Co., Boston, Mass., 1991.

Womack, J., Jones, D. and D. Roos, The Machine that Changed the World: The Story of Lean Production, Harper Perennial Press, New York, 1990. 